\title{
Integrated systems biology and imaging of the smallest free-living eukaryote Ostreococcus tauri
}

Authors: Chuck R. Smallwood ${ }^{1}$, Jian-Hua Chen², Neeraj Kumar ${ }^{1}$, William Chrisler ${ }^{1}$, Samuel O. Purvine $^{1}$, Jennifer E. Kyle ${ }^{1}$, Carrie D. Nicora ${ }^{1}$, Rosanne Boudreau², Axel Ekman², Kim K. Hixson ${ }^{1}$, Ronald J. Moore ${ }^{1}$, Gerry McDermott ${ }^{2}$, William R. Cannon ${ }^{1}$ \& James E. Evans ${ }^{1,3^{*}}$

\section{Affiliations:}

1) Earth and Biological Sciences, Pacific Northwest National Laboratory, 902 Battelle Blvd., Richland, WA 99354, USA

2) Department of Anatomy, School of Medicine, UCSF, San Francisco, CA 94110, USA; Molecular Biophysics and Integrated Bioimaging, Lawrence Berkeley National Laboratory, Berkeley, CA 94720, USA

3) School of Biological Sciences, Washington State University, Pullman, WA 99164, USA.

Corresponding Author: james.evans@pnnl.gov 


\section{Abstract:}

Ostreococcus tauri is an ancient phototrophic microalgae that possesses favorable

3

\section{Introduction}

\section{Keywords:} genetic and cellular characteristics for reductionist studies probing biosystem design and dynamics. Here multimodal bioimaging and multi-omics techniques were combined to interrogate $O$. tauri cellular changes in response to variations in bioavailable nitrogen and carbon ratios. Confocal microscopy, stimulated Raman scattering, and cryo-soft x-ray tomography revealed whole cell ultrastructural dynamics and composition while proteomic and lipidomic profiling captured changes at the molecular and macromolecular scale.

Despite several energy dense long-chain triacylglycerol lipids showing more than 40 -fold higher abundance under $\mathrm{N}$ deprivation, only a few proteins directly associated with lipid biogenesis showed significant expression changes. However, the entire pathway for starch granule biosynthesis was highly upregulated suggesting much of the cellular energy is preferentially directed towards starch over lipid accumulation. Additionally, three of the five most downregulated and five of the ten most upregulated proteins during severe nitrogen depletion were unnamed protein products that warrant additional biochemical analysis and functional annotation to control carbon transformation dynamics in this smallest eukaryote.

systems biology, proteomics, lipidomics, biofuel, microalgae, photosynthesis, oleaginous, triacylglycerol, lipid, starch, carbon transformation, lipid droplet, nitrogen scavenging, soft x-ray tomography, stimulated raman scattering microscopy, fluorescence microscopy 
phylogenetically diverse and exhibit varying cellular phenotypes that naturally produce high

27 value metabolites, proteins, carbohydrates and energy dense lipids that can be exploited for a wide array of industrial applications ${ }^{1-3}$. Due to their high photosynthetic efficiency for energy conversion, and minimal growth requirements consisting of sustainable resources such as marine or brackish media, light, $\mathrm{CO}_{2}$ and trace vitamins, microalgae are prime bioproduction

31 platforms ${ }^{4,5}$.

Triacylglycerol (TAG) lipids are significantly enhanced when microalgae are subjected to

33 cellular stressors such as light, temperature, and nutrient deprivation ${ }^{6}$. TAG lipids possess

34 nonpolar character and are stored in anhydrous, high-density organelles called lipid bodies,

35 which are desirable for industrial lipid feedstock applications ${ }^{7}$. For other oleaginous algae, TAG

36 production can be triggered by nutrient deprivation of iron, sulfur, nitrogen, phosphate, or silicon

376 . In most eukaryotes, combinatorial reduction of these nutrients results in altered levels of growth-associated structural lipids (phospholipids) and energy storage lipids (TAG) products ${ }^{8,9}$.

39 Unfortunately, in most cases starvation or deprivation can be detrimental to cell viability and

40 overall growth capacity thereby limiting cell biomass yields needed for viable lipid feedstock

41 industrial applications ${ }^{10}$. While several reports have shown that supplementing additional C

42 sources when combined with $\mathrm{N}$ depletion for certain organisms can yield increased growth and

43 lipid accumulation rates compared to strict starvation $2,11,12,13$, a detailed understanding of the

44 interplay between carbon and nitrogen bioavailability is needed to advance bioproduction

45 applications.

Studying phototrophic metabolism in primitive species, such as the prasinophyte

47 Ostreococcus tauri can provide convenient opportunities to define minimal and critical metabolic

48 pathways for $\mathrm{C}$ transformation ${ }^{14,15,16}$. O. tauri is the smallest known free-living eukaryote

49 ( 0.8 $\mu \mathrm{m}$ in thickness), lacks a cell wall, and thrives in varying photic, toxic and thermal ecosystems ${ }^{17-19}$. It also has a highly condensed genome with only $\sim 8,000$ genes $^{20}$ so most 
51 reactions are governed by a single enzyme (rather than multiple duplicating function enzymes)

52 which simplifies engineering requirements and interpretation. For example, the canonical model

53 green alga Chlamydomonas has 4 copies of Acetyl-CoA Carboxylase (E.C. 6.4.1.2) whereas

54 Ostreococcus has only 1 enzyme of that class. In addition, a recent study ${ }^{21}$ reported the genetic

55 diversity associated with large phenotypic differences between Ostreococcus strains

56 highlighting the uncharted abundance of genetic biodiversity. These characteristics make $O$.

57 tauri a potential candidate for future industrial applications. However, considerable biodesign

58 efforts will likely be needed to develop an efficient cell factory for controlled and cost-effective

59 bioproduction of lipid feedstocks or other high value metabolites. Here, an integrated analysis

60 of bioimaging, proteomic, and lipidomic characterization was used to investigate 0 . tauri cellular

61 response to varying $\mathrm{C}: \mathrm{N}$ ratios. Our results provide additional understanding of $\mathrm{C}$ storage and

62 energy transformation pathways within the microalgae $O$. tauri and identify new proteins to

63 target for future engineering efforts.

65 Results

66 Other than the bioavailable C:N ratio, all other experimental parameters (e.g.,

67 temperature, duration, diurnal cycling, light fluence, etc.) were kept constant throughout this

68 study. The four different media conditions used herein are designated as $\mathrm{K} 6 \mathrm{CN}, \mathrm{K} 2 \mathrm{CN}, \mathrm{K} 2 \mathrm{C}$

69 and $\mathrm{K} 6 \mathrm{C}$ which are listed in decreasing $\mathrm{C}: \mathrm{N}$ ratio. The normal growth media for $\mathrm{O}$. tauri is Keller

70 Media (referenced herein as $\mathrm{K} 2 \mathrm{CN}$ media) and contains $\sim 2.5 \mathrm{mM}$ bicarbonate and $0.9 \mathrm{mM}$ total

71 nitrogen. To streamline interpretation, bicarbonate was kept as the sole media carbon source.

72 For K6CN media the nitrogen content was kept equivalent, but the bicarbonate increased to

$736 \mathrm{mM}$ providing elevated carbon but normal nitrogen conditions. The use of $6 \mathrm{mM}$ bicarbonate as

74 the elevated carbon set point was chosen following an initial growth screen of $O$. tauri in $\mathrm{K}$

75 media supplemented with various levels of bicarbonate from 0-10mM where $6 \mathrm{mM}$ showed 
highest growth response with healthy chlorophyll ratios per cell. The final two media conditions

$77 \mathrm{~K} 2 \mathrm{C}$ and $\mathrm{K} 6 \mathrm{C}$ share the same composition as $\mathrm{K} 2 \mathrm{CN}$ and $\mathrm{K} 6 \mathrm{CN}$ but are depleted of all nitrogen

78 sources. Thus all subsequent experiments consisted of 4 conditions of decreasing C:N

79 bioavailable ratios from elevated carbon with normal nitrogen $(\mathrm{K} 6 \mathrm{CN})$, to normal carbon with

80 normal nitrogen $(\mathrm{K} 2 \mathrm{CN})$, to normal carbon with no nitrogen $(\mathrm{K} 2 \mathrm{C})$, and elevated carbon with no

81 nitrogen (K6C).

82 Diurnal cycling with 12:12 hour light:dark cycles was used to synchronize cellular

83 division and growth, and samples were harvested 3 hours after light to dark transition. Cell

84 growth was monitored by absorbance at 750nm (measure of particulates) and 680nm (measure

85 of chlorophyll a) for up to 144 hours (Fig. 1B). Decreases in absorbance at $680 \mathrm{~nm}$ were typical

86 of $\mathrm{K} 2 \mathrm{C}$ and $\mathrm{K} 6 \mathrm{C}$ cell cultures relative to $\mathrm{K} 2 \mathrm{CN}$ and $\mathrm{K} 6 \mathrm{CN}$. Absorbance at 750nm exhibited

87 similar decreases for $\mathrm{N}$ deprived cultures versus $\mathrm{N}$ replete. However, when comparing normal $\mathrm{C}$

88 to excess $\mathrm{C}$ for either $\mathrm{N}$ replete or $\mathrm{N}$ deprived conditions, cultures with excess $\mathrm{C}$ consistently

89 displayed higher A680 and A750 values. Confocal fluorescence microscopy was used to

90 compare phenotypes for a couple dozen cells from each condition whereas fluorescence

91 activated cell sorting (FACS) allowed quantitative analysis of larger population dynamics every

9224 hours. In both case, dramatic increases of neutral lipid (NL) content were detected for K2C

93 and K6C conditions (Fig. 1 C-F). Interestingly K6CN (Fig. 1C) cell cultures only exhibited subtle

94 differences between NL and some increases in phospholipid (PL) intensity indicating some

95 photosynthetic lipid metabolism difference to K2CN (Fig. 1D). Since confocal microscopy can

96 only track dynamics for fluorescently labelled components, label-free cell ultrastructure and

97 composition changes were also evaluated.

98 Cryogenic soft x-ray nanotomography (CSXT) was performed on 72-hour cell cultures to

99 increase resolution and highlight native cellular features of intracellular lipid accumulation (Fig.

100 1E). Dark subcellular features, assigned as vacuoles due to their linear absorption coefficient 
101 (LAC), were observed in the intracellular cytosolic space of cells in K6CN and K2CN culture

102 conditions, but no vacuoles were observed for K2C and K6C cultured cells. The vacuoles were

103 much larger in $\mathrm{K} 6 \mathrm{CN}$ compared to $\mathrm{K} 2 \mathrm{CN}$ conditions. Based on studies conducted in other algae

104 and plants starch is likely present in the chloroplast ${ }^{20}$. However, intracellular starch was

105 undetected in $O$. tauri cells via X-ray nanotomography likely due to the density appearing similar

106 to or masked by the surrounding tissues with a similar LAC - possibly due to its small cell size or

107 chloroplast packing density. Therefore, stimulated Raman scattering (SRS) microscopy was

108 used as a second label-free imaging method to identify relative abundance of intracellular starch

109 accumulation. Interestingly, starch was detected in the chloroplast for all tested conditions.

110 However, the starch seen for $\mathrm{K} 2 \mathrm{C}$ was minimal (Supplemental Figure 1). Considering that K6C

111 represents an even more deprived nitrogen to carbon ratio compared to $\mathrm{K} 2 \mathrm{C}$, it was anticipated

112 that $\mathrm{K} 6 \mathrm{C}$ would show the lowest levels of starch since both conditions also show significant lipid

113 accumulation. However, the increase in starch content for K6C suggests that these cells still

114 have abundant carbon available for transformation into carbohydrates, and potential future

115 engineering efforts could focus on knocking out genes associated with starch accumulation to

116 divert this excess energy toward lipid feedstock production instead.

117 The confocal imaging also happened to capture a possible lipid droplet secretion event.

118 During live-cell imaging, a single cell was captured over a few minutes showing the formation of

119 a cellular bleb containing a single lipid droplet that was released in subsequent scans

120 (Supplemental Figure 2). We have previously reported that this organism does not appear to

121 have any canonical proteins associated with lipid droplet secretion from other organisms ${ }^{22}$. That

122 study also captured static images showing what was described as blebbing intermediates. The

123 current image series reported here is the first case in which the process was observed live

124 thereby lending additional support to the theory that $O$. tauri is capable of lipid droplet secretion

125 although the detailed mechanism remains elusive. 
Dramatic changes observed for lipid staining profiles prompted the exploration of

127 underlying global proteomic expression profiles for each experimental culture condition.

128 Cultures were harvested at 24- and 48-hour time points for LC-MS/MS proteomics to obtain a

129 measure of global proteomic expression. These time-points were chosen for comparison since

130 they showed the biggest relative 24-hour changes via FACS and confocal analysis. The

131 proteomics data was mapped into individual metabolic groups (synthesis, degradation, energy,

132 other and non-metabolic pathways) to interpret relative changes of cells cultured in $\mathrm{K} 6 \mathrm{CN}$,

$133 \mathrm{~K} 2 \mathrm{CN}, \mathrm{K} 2 \mathrm{C}$ and $\mathrm{K} 6 \mathrm{C}$ conditions for each metabolic pathway (Fig. 2). Of particular note was the

134 increased changes in abundance for both $\mathrm{K} 2 \mathrm{C}$ and $\mathrm{K} 6 \mathrm{C}$ in the carbohydrate synthesis pathway

135 compared to $\mathrm{K} 2 \mathrm{CN}$ and $\mathrm{K} 6 \mathrm{CN}$. However, very few proteins within the fatty acid (FA)/lipid

136 synthesis pathways showed significant, if any, change in abundance despite bioimaging

137 observations of cellular lipid increases up to $60 \%$ the volume of cells. For example, while DGAT,

138 the canonical enzyme representing the last committed step of TAG synthesis was detected with

139 global proteomics, it's abundance remained effectively equivalent across all 4 sample

140 conditions.

141 High $\mathrm{C}$ to $\mathrm{N}$ ratio of K6C displayed consistently higher proteomic responses compared to

$142 \mathrm{~K} 2 \mathrm{C}$ for upregulated proteins related to $\mathrm{C}$ storage. The complete starch pathway was detected

143 with ascending upregulation from alpha amylase to granule-bound starch synthetase (GBSSI)

144 for N depletion conditions. GBSSI was the third highest upregulated protein overall highlighting

145 the reliance on carbon storage under these conditions. Previous studies have found similar

146 results for $\mathrm{GBSSI}^{23}$. N deprivation also caused downregulation of proteins involved in $\mathrm{N}$

147 acquisition, such as nitrate transporters, nitrate reductase with concomitant upregulation of $\mathrm{N}$

148 scavenging proteins for glutamine, asparagine, and urea. Much of the downregulated proteins

149 detected were ribosome based or were proteins localized to the chloroplast. 
Overall 471 unnamed protein products were found to be upregulated or downregulated

151 with several exhibiting some of the most extreme abundance changes (Fig. 4). $\mathrm{N}$ deplete

152 conditions $\mathrm{K} 2 \mathrm{C}$ and $\mathrm{K} 6 \mathrm{C}$ had similar distributions of upregulated and downregulated protein

153 trends, with more increased upregulation of proteins for excess carbon cultures. For K6C, 5 of

154 the 10 most upregulated and 3 of the 10 most downregulated were UPP (Fig. 3). Interestingly,

155 several of these proteins show inversion of abundance for replete versus depleted $\mathrm{N}$ conditions.

156 XP_003075209 (ostta02g03680), XP_003081059 (ostta09g00670), XP_003078347

157 (ostta03g04500) all exhibit significant upregulation under K6CN and K2CN conditions at 48

158 hours compared to $\mathrm{K} 2 \mathrm{CN}$ at 24 hours, however, these proteins show significant downregulation

159 for $\mathrm{K} 2 \mathrm{C}$ and $\mathrm{K} 6 \mathrm{C}$ conditions at 48 hours. The biggest change was seen for XP_003078347

160 (ostta03g04500) which was had a log2 value change of -0.54 for K6CN but a value of 1.96 for

161 K6C. Similarly, other unnamed proteins XP_003084215 (ostta18g01710), XP_003082140

162 (ostta11g03180) and XP_003082699 (ostta13g02170) were all downregulated for K6CN and

$163 \mathrm{~K} 2 \mathrm{CN}$ at 48 hours but upregulated for K2C and K6C. Clearly these unnamed proteins are

164 dramatically affected by the bioavailable ratio of $\mathrm{C}$ and $\mathrm{N}$ and represent interesting targets for

165 future in-depth functional annotation.

Conducting a BLAST alignment analysis on the UPP identified in these runs resolved a

167 predicted membrane protein (XP_003080099 (ostta06g04530)) upregulated for N depleted

168 conditions $\mathrm{K} 2 \mathrm{C}$ and $\mathrm{K} 6 \mathrm{C}$, which was identified as having a domain with homology to TMEM14,

169 an uncharacterized superfamily believed to be involved in membrane transport of lipids in higher

170 eukaryotes. This protein could possibly play a role in the lipid droplet secretion from 0 . tauri.

171 Other potentially interesting unknown protein products were also uncovered during BLAST

172 alignments with two notable probable identifications: A putative Acyl-CoA N-acyltransferase

173 (XP_003084085.1 (ostta18g00460)) slightly upregulated for K2CN and K2C but not K6CN or

174 K6C; and a putative Zinc finger (XP_003080741.1 (ostta08g01730)) slightly downregulated for 
$175 \mathrm{~K} 6 \mathrm{CN}, \mathrm{K} 6 \mathrm{C}$, and $\mathrm{K} 2 \mathrm{C}$ conditions, which have been known to participate in a number of

176 eukaryotic cellular mechanisms including lipid binding. Additional proteins such as sarcosine-

177 dimethyltransferase (SDMT), an enzyme found in the betaine biosynthesis pathway in other

178 algae and higher plants related to osmoprotection during cellular stress ${ }^{24,25}$, were found to be

179 elevated only for $\mathrm{K} 2 \mathrm{C}$ and $\mathrm{K} 6 \mathrm{C}$ conditions, which may reinforce cellular stability during $\mathrm{N}$ stress

180 and lipid accumulation.

181 Despite observing limited changes in the proteome related to lipid metabolism, the visual

182 confocal and FACS analysis provided ample evidence of significant lipid accumulation that

183 warranted further characterization to understand cellular lipid composition and relative

184 abundance. Thus, the same $\mathrm{K} 6 \mathrm{CN}, \mathrm{K} 2 \mathrm{CN}, \mathrm{K} 2 \mathrm{C}$, and $\mathrm{K} 6 \mathrm{C}$ cultures were surveyed at the same

185 24- and 48-hour time-points using LC-MS/MS global lipidomics analysis. Quantitative lipid

186 profiles were collected for more than 280 lipids (Supplemental Figures $3-9$ ). The $\mathrm{N}$ depletion

187 conditions (K2C and $\mathrm{K} 6 \mathrm{C}$ ) resulted in significant increases of energy dense TAG lipids with

188 more than 10 TAGs showing $>40$-fold increase in abundance already at 48-hours. The FACS

189 and confocal analysis showed that the NL content continues to accumulate well beyond 48

190 hours. In comparison, TAG lipid abundance was flat or decreased for K6CN and K2CN

191 conditioned cells, indicating that cells were not diverting C into lipid energy storage during

192 nutrient rich conditions although they were still accumulating starch as seen from SRS

193 (Supplemental Figure 1). The observed FA profiles provide additional support for recently

194 reported ${ }^{26}$ unique long chain FAs despite lacking annotated enzymes known to synthesize

195 them, indicating that $O$. tauri is at the very least an intriguing oleaginous organism for lipid

196 feedstock development. In addition, the number of long chain FAs in TAGs were significantly

197 enhanced during K6C conditions, demonstrating this organism's capacity to uptake and

198 transform excess C into long chain energy dense lipids without genetic modification

199 (Supplemental Figures 7-9). 
Changes in structural lipids were also detected (Supplemental Figures $3-6$ ).

201 Thylakoidal membranes are composed of monogalactosyldiacylglycerol (MGDG) and

202 digalactosyldiacylglycerol (DGDG), which stabilize the thylakoid for maximal photosynthetic

203 efficiency ${ }^{27}$. In addition, algal thylakoid membranes contain abundant amounts of

204 sulphoquinovosyldiacylglycerol (SQDG) which contributes to increased stability in the

205 photosynthetic harvesting complexes and accommodates membrane protein associations

206 unique to microalgae ${ }^{28}$. Increased abundances for MGDG and 3- to 7-fold increases in DGDG

207 were detected for $\mathrm{K} 2 \mathrm{C}$ and $\mathrm{K} 6 \mathrm{C}$ conditions, with $\mathrm{C} 16$ chain lengths exhibiting the most

208 abundant and dramatic changes during N depletion. C16 chain length SQDG lipids were also

209 slightly upregulated for K6C, suggesting they may be adding stability to light harvesting

210 complexes or membrane protein expression unique to excess $\mathrm{C}$ exposure and $\mathrm{N}$ depletion.

\section{Discussion}

Linkages between $\mathrm{N}$ and $\mathrm{C}$ metabolism related to lipid biogenesis were interrogated for

214 the microalgae Ostreococcus tauri. Single cell and population imaging experiments combined

215 with global proteomic and lipidomic experiments on the same cultures demonstrated that even

216 the simplified cell architecture and genome of $O$. tauri displays complicated regulatory linkages

217 as a function of bioavailable carbon to nitrogen ratios. Cryogenic soft x-ray nanotomography

218 revealed distinct lipid droplet distributions of varying sizes confirming initial fluorescence

219 microscopy results. K2C conditioned cells had uniform sized lipid droplets whereas cells in K6C

220 conditions had lipid droplets of varying size including very large lipid droplets that swelled and

221 deformed the cells.

222 Numerous photosynthetic, structural, and energy storage fatty acid (FA)/lipids were

223 verified through LC-MS/MS lipidomic analysis that included detection of long chain TAGs, ideal

224 for lipid feedstocks. Proteomic data combined with physiological cell responses to varying $\mathrm{C}$ and 
$225 \mathrm{~N}$ revealed that although FA/lipid synthesis pathways had little proteomic changes,

226 carbohydrate synthesis proteomics was independently upregulated. Both ribulose 1,5-

227 biphosphate carboxylase/oxygenase large and small subunits (Rubisco) were slightly

228 downregulated for $\mathrm{K} 2 \mathrm{C}$ and $\mathrm{K} 6 \mathrm{C}$ relative to $\mathrm{K} 2 \mathrm{CN}$ suggesting Rubisco expression in

229 Ostreococcus contains minimum concentrations of Rubisco to support normal growth as

230 reported for other organisms ${ }^{29}$. Restricting protein identifications to subsets related to

231 carbohydrate conversion, $\mathrm{N}$ scavenging, and energy regulation allowed for the simplification of

232 biological interpretations related to lipid feedstock optimization targets. The most upregulated

233 protein was a protein kinase involved in serine/threonine phosphorylation and was equally

234 upregulated for $\mathrm{K} 2 \mathrm{C}, \mathrm{K} 6 \mathrm{C}$, and $\mathrm{K} 6 \mathrm{CN}$ conditions, which could possibly play a role in regulating

235 diurnal cycling or stress response since $\mathrm{K} 6 \mathrm{CN}$ could also be seen as another $\mathrm{N}$ deprived state

236 relative to available C. GBSSI was the third most upregulated protein in all and was more

237 upregulated in $\mathrm{K} 6 \mathrm{C}$ than $\mathrm{K} 2 \mathrm{C}$. Knock-down of GBSSI could potentially provide a redirection of

238 O. tauri metabolism to less starch accumulation and more lipid accumulation under K6C

239 conditions.

240 In addition to the proteins related to energy storage, increased abundances of proteins

241 related to lipid viability, lipid production, and osmotic shock were detected to varying degrees.

242 Finally, a surprising number of proteins of unknown function and identity were revealed to be

243 part of the 10 most significant proteomic increases and decreases overall and each is a

244 potential target for future engineering efforts. A recent study focused on circadian protein

245 regulation ${ }^{30}$ identified ostta03g04500, ostta09g00670, and ostta02g03680 proteins of unknown

246 function that happen to overlap with the findings reported here. This suggests that the proteins

247 found in both studies may have a co-relational effect between carbon and nitrogen

248 bioavailability and the circadian cycle. Delving further into the function of these individual

249 proteins will be important for understanding their real role in overall cellular regulation and 
250 metabolic processes. Furthermore, the wealth of undefined proteins emphasizes the extent of

251 unexplored opportunities related to N, C, and energy storage pathways, and highlights the

252 peculiar genetic diversity within natural populations of Ostreococcus and possibly other primitive

253 marine species.

255 Methods:

256 Strain maintenance, culture growth media, and nutrient starvation conditions

257 O. tauri cell cultures were obtained from the Roscoff Culture Collection (RCC745); strain name:

258 OTTH0595, which has been fully sequenced ${ }^{20}$. Cultures of RCC745 were grown in defined

259 Keller $(\mathrm{K})$ media ${ }^{31}$ with normal or depleted $\mathrm{N}$ and $\mathrm{HCO}_{3-}: \mathrm{K} 2 \mathrm{CN}$ contained normal $\mathrm{N}$ and $\mathrm{C}$,

$260 \mathrm{~K} 6 \mathrm{CN}$ with normal $\mathrm{N}$ and $6 \mathrm{mM} \mathrm{HCO}_{3-}, \mathrm{K} 2 \mathrm{C}$ with depleted $\mathrm{N}$ and $2.5 \mathrm{mM} \mathrm{HCO}_{3-}$, and $\mathrm{K} 6 \mathrm{C}$ with

261 depleted $\mathrm{N}$ and $6 \mathrm{mM} \mathrm{HCO}_{3-}$. All Keller media-based culture conditions were prepared in fresh

262 artificial seawater (ASW) with defined amounts of nutrients analytically prepared fresh and

263 sterile filtered prior to each experiment. To monitor growth and lipid accumulation over time

264 absorbance at $680 \mathrm{~nm}$ and $750 \mathrm{~nm}$ was measured to obtain both values for chlorophyll content

265 and particulate matter, respectively, for each culture. Graphing the ratio of $750 \mathrm{~nm} / 680 \mathrm{~nm}$

266 provided a measure of chlorophyll functional efficiency as well as possible lipid particulates in

267 solution. Graphical analysis of each growth and starvation curve required minimal normalization

268 due to our consistent efforts in capturing cells during mid-log stages of growth. For growth and

269 lipid accumulation studies cells were grown initially in normal $\mathrm{K}$ media to approximately 0.03 at

270 OD680 then gently centrifuging cultures at 1200XG for 10 minutes in a swing bucket rotor,

271 washed with respective defined $\mathrm{K}$ media, and resuspending cells into defined $\mathrm{K}$ media at a

272 target 0.03 at OD680 and continued diurnal light entrainment for specified time courses in

273 sealable CytoOne non-treated cell culture flasks (USA Scientific, USA) with mixing of cultures

274 once per 24 hours. To prepare cell cultures for starvation surveys they were gently centrifuged 
275 fresh cultures at $2200 \times \mathrm{xG}$ for 10 mins with swing bucket rotor centrifugation and washed cell

276 pellets once with defined K media of interest then suspended cells in defined media conditions

277 and continued diurnal light entrainment for specified time courses in sealable CytoOne non-

278 treated cell culture flasks (USA Scientific, USA) with mixing of cultures once per 24 hours.

Fluorescence activated cell sorting analysis of intracellular lipid content

O. tauri cells were cultured to mid log phase and gently centrifuged to concentration then

282 stained with Nile Red $(4.8 \mu \mathrm{g} / \mathrm{mL})$ lipid stain for exactly 10 mins before each experimental

283 measurement on the BD INFLUX flow cytometer (BD Biosciences, San Jose, CA, USA). FSC

284 and SSC were used to gate out any non-specific cellular debris. Specific gating in the range of

285 known cell size of $O$. tauri was used to determine the fluorescence from stained neutral lipid

286 (488/542 $\pm 13.5 \mathrm{~nm})$, phospholipid (561/615 $\pm 12 \mathrm{~nm})$, and natural chlorophyll autofluorescence

$287(640 / 670 \pm 15 \mathrm{~nm})$ for defined populations of cells. Each individual FACS experiment was

288 calibrated to 3.6 ide scatter 10 mins before running our sample measurements in defined media

289 cultures. The fluorescence intensity of neutral lipid and phospholipid fluorescence intensity at

290 specific time points was compared in scatter plots to demonstrate population dynamics for each

291 sample condition. K2CN at 24 hours was used as the baseline for normal conditions to detect

292 changes due to varying C:N bioavailability.

294 Fluorescence and SRS confocal microscopy

Confocal images were obtained on Zeiss LSM 710 (Carl Zeiss AG, Germany) confocal

296 microscope with a 100x oil immersion objective. An InTune Laser with 505nm and 535nm light

297 was used to maximize the separation of the triglyceride (585nm) and phospholipid (638nm)

298 emission peaks while diminishing crosstalk of the Nile Red stained cells. In addition, chlorophyll

299 autofluorescence was excited with 405nm light and monitored the emission profile at $680 \mathrm{~nm}$. 
300 Nile Red stained cells were immobilized on glass slides with poly-L-lysine and imaged

301 immediately with z-scan slicing of $0.43 \mu \mathrm{m}$ to survey whole cell fluorescence labeling distribution.

302 All fluorescence channels were set with identical gain and laser power settings to provide

303 relative levels of fluorescent intensity and no adjustments of contrast or gain were applied to

304 fluorescence imaging during post processing. 0 . tauri cultures were grown in $15 \mathrm{~mL}$ falcon tubes

305 in a $12: 12$ light:dark illumination $\left(\sim 20 \mu \mathrm{mol} / \mathrm{m}^{2} / \mathrm{s}\right)$ at $25^{\circ} \mathrm{C}$ for 96 hours, harvested by gentle

306 centrifugation (1000xG, 5 mins) and concentrated equally to 10x original cell density for

307 imaging. Concentrated cell suspensions were then stained with Nile Red (4.8 $\mu \mathrm{g} / \mathrm{mL})$ for 10

308 minutes and then $3 \mu \mathrm{L}$ of the labeled culture were mounted on poly-lysine treated microscope

309 slides (Electron Microscopy Sciences, USA) for confocal fluorescence and SRS imaging.

310 Fluorescence and SRS confocal microscopy were conducted on the Nile Red stained O. tauri

311 cells using a Leica DMi8 (Leica Microsystems GmbH, Germany) inverted confocal microscope

312 (a 63x/1.20na water immersion objective) integrated with an APE picoEmerald laser consisting

313 of a 2.5 ps pulsed tunable pump and $1031 \mathrm{~nm}$ stokes with the SRS detection module and an

314 EOM Modulator. Prior to the SRS detection, the stokes beam was blocked by a FESH1000 filter

315 (Thorlabs, USA). The SRS signal was detected on a $10 \times 10 \mathrm{~mm}$ photodiode connected to the

316 APE lock-in amplifier. For starch detection the SRS pump signal was tuned to $947 \mathrm{~nm}$ at $152 \mathrm{~mW}$

317 with bandwidth of $0.7 \mathrm{~nm}$ with the stokes power at $150 \mathrm{~mW}$ modulated by the integrated EOM,

318 and a delay of $3500 f$ s to detect the $860 \mathrm{~cm}^{-1}$ peak of starch ${ }^{32}$. Cellular chlorophyll was excited

319 with a $638 \mathrm{~nm}$ laser with $1 \%$ power and fluorescence signal collected with emission range of

$320677-689 \mathrm{~nm}$. Neutral lipid fluorescence from Nile Red staining was excited with 552nm with $1 \%$

321 laser power and emission 575-583nm. Sequential acquisition of different channels was

322 acquired at $1024 \times 1024$ format, with slower 400 scan speeds, and 4x zoom. Maximum

323 thresholds were changed consistently for all SRS starch images to obtain equal post processing

324 values across all samples; no post processing was conducted on either chlorophyll or neutral 
325 lipid channels.

\section{Cryogenic Soft X-ray Tomography for Intracellular Distribution of Organelles} $20 \mu \mathrm{E}$. Cell cultures were incubated with 12-hour diurnal light at RT and harvested by

331 centrifugation at 48,72 and 96 -hour time points. Cells were gently centrifuged at $1000 x G$ for

33210 mins to pellet. Pelleted cells had all but $\sim 5 \mu \mathrm{L}$ of supernatant removed to remove a viscous

333 cell biomass. Wet cell biomass was inserted into $5 \mu \mathrm{m}$ micro capillaries and plunge frozen in cold

334 liquid propane. In some cases, $6 \mu \mathrm{m}$ polystyrene beads were added to cell suspensions prior to

335 centrifugation to minimize the impact of freezing on large lipid containing cells. Frozen

336 capillaries were stored in liquid nitrogen until imaging by the soft $x$-ray light source. Soft $x$-ray

337 data acquisition was carried out on beamline 2.1, a soft x-ray microscope in the National Center

338 for X-Ray Tomography (NCXT) located at the Advanced Light Source in Berkeley, California ${ }^{33}$.

339 The microscope soft x-ray illumination was generated by a bend-magnet in the synchrotron

340 lattice and focused onto the specimen by a Fresnel Zone Plate (FZP) condenser. Specimen

341 illumination was order-sorted by a pinhole positioned just in front of the specimen. A second

342 zone plate, located downstream of the specimen, magnified and focused an image of the

343 specimen on a CCD detector. During data collection, the cells were maintained in a stream of

344 helium gas that had been cooled to liquid nitrogen temperatures. Each tomographic dataset

345 (i.e., 90 projection images spanning a range of $180^{\circ}$ ) was collected using Fresnel zone plate

346 based objective lens with a resolution of $50 \mathrm{~nm}$. Exposure times for each projection image

347 ranged from 150 to $300 \mathrm{msec}$. The software suite AREC3D was used to align the projection

348 images calculate tomographic reconstructions ${ }^{34}$. 


\section{Lipid Extraction and Lipidomics Using Liquid Chromatography Tandem Mass}

\section{Spectrometry}

Each $O$. tauri culture was harvested at specific time points and ultimately spun down at

$3533000 \times \mathrm{g}$ for $10 \mathrm{~min}$ to form a pellet in chloroform compatible $2 \mathrm{~mL}$ Safe Seal microfuge tubes

354 (Sorenson Bioscience, Inc, Salt Lake City, UT). The supernatant was removed, and the wet

355 pellet was weighed for an estimate of biomass, then a mixture of $1 \mathrm{~mL}$ of methanol, $0.5 \mathrm{~mL}$ of

356 chloroform and $0.4 \mathrm{~mL}$ of nanopure water was added to each pellet. The pellets were vortexed

357 and sonicated for about $10 \mathrm{sec}$ in a bath sonicator and the mixture was allowed to stand at room

358 temperature for $10 \mathrm{~min}$. Then an additional $0.5 \mathrm{~mL}$ of chloroform and $0.5 \mathrm{~mL}$ of water were

359 added, and the mixtures were shaken vigorously into an emulsion. Each sample was

360 centrifuged at $10,000 \times \mathrm{g}$ for $10 \mathrm{~min}$. The bottom chloroform layer was carefully removed from

361 the separated solvent layers using a Pasteur pipette and taking care not to take up any of the

362 protein disc or the top polar layer and was placed in a pre-weighed glass auto sampler vial. The

363 bottom lipid layer was dried down overnight under nitrogen and the vials with the total lipid

364 extract (TLEs) were weighed to obtain the total mass. $5 \mu \mathrm{L}$ of chloroform was added to each

365 dried sample and then the sample diluted to $50 \mu \mathrm{g} / \mu \mathrm{L}$ with methanol. The samples were then

366 stored at $-20^{\circ} \mathrm{C}$ until ready for mass spectrometric analysis.

367 Extracted lipids were dried down then reconstituted in methanol. The TLEs were

368 analyzed by LC-MS/MS using a Waters NanoAquity UPLC system interfaced with a Velos

369 Orbitrap mass spectrometer (Thermo Scientific, San Jose, CA) as outlined in Dautel et al.

$3702017^{35}$. LC-MS/MS raw data files were imported into the in-house developed software LIQUID ${ }^{36}$

371 for identification of lipid molecular species. Manual validation of the lipid identifications were

372 determined by examining the tandem mass spectra for diagnostic ion fragments along with

373 associated chain fragment information. In addition, the isotopic profile, extracted ion

374 chromatogram (XIC), and mass error of measured precursor ion were examined for lipid 


\section{Cellular Protein Extraction and Digestion}

To the remaining protein/debris pellet obtained from the lipid extraction, $1 \mathrm{~mL}$ of ice cold methanol was added $3 x$ to wash the majority of residual metabolites away from the pellet. A

379 Filter-Aided Sample Prep (FASP) protein extraction and trypsin digestion was then performed 380 using the FASP protein digestion kit (Expedeon, San Diego CA) using manufacturer's

381 suggested protocol (Erde J et al, 2014, J Proteome Res 13(4):1885-1895). Briefly, methanol

382 washed pellets were air dried for $2 \mathrm{hrs}$ and were resuspended in solubilization buffer of $12 \mathrm{mM}$

383 deoxycholate, $12 \mathrm{mM} \mathrm{N}$-lauroyl sarcosine with $10 \mathrm{mM}$ TCEP, and $200 \mathrm{mM}$ ammonium

384 bicarbonate, $\mathrm{pH} 8.0$ at an approximate concentration of $13 \mu \mathrm{g} / \mu \mathrm{L}$. $30 \mu \mathrm{L}$ of this protein solution

385 was then mixed with $200 \mu \mathrm{L}$ of urea sample solution (kit provided), the sample was centrifuged

386 on the kit provided spin filter at $14,000 \times \mathrm{g}$ for $15 \mathrm{~min}$. Washes with urea and ammonium

387 bicarbonate along with trypsin digestion and alkylation with iodoacetamide were carried out as

388 the kit specifies. Peptides were then suspended in nanopure water and peptides were then

389 quantified using a BCA assay (Pierce, Rockford IL) with a bovine serum albumin standard.

\section{$391 \quad$ ITRAQ Peptide Labeling}

Peptides were labeled with 8-plex iTRAQ (AB Sciex, Redwood City, CA) reagents as

393 described below. $100 \mu \mathrm{g}$ of each peptide sample was placed in a new tube and dried down.

394 Chanel designations are as follows: $43 \mu \mathrm{g}$ of dissolution buffer (iTRAQ buffer kit) was added to 395 each sample, these being vortexed into solution and centrifuged briefly to draw sample to the 396 bottom of each tube. The iTRAQ reagent $(30 \mu \mathrm{L})$ was diluted further with isopropanol (115 $\mu \mathrm{L})$ 397 and this was then added to each sample. Each reaction was carried out at RT for 2 hrs, with 50 $398 \mathrm{mM}$ ammonium bicarbonate $(200 \mu \mathrm{L})$ added to quench each reaction tube. After $1 \mathrm{hr}$, the 399 contents from all iTRAQ channel reactions were added to one tube and then the sample was 
400 vortexed and dried down in a speed vac. The labeled peptides were cleaned up using C-18

401 SPE columns (SUPELCO Discovery) were then employed to remove the salts, using a $0.1 \%$

402 TFA in nanopure water to wash the peptides and $80 \%$ acetonitrile, $0.1 \%$ TFA in water to elute

403 the peptides.

404

405 Offline Fractionation of Peptides and Preparation of Proteome Samples

$406400 \mu \mathrm{g}$ of iTRAQ labeled peptides were separated using an off-line high $\mathrm{pH}(\mathrm{pH} 10)$ reversed-

407 phase (RP) separation with a Waters XBridge C18 column (250 mm x $4.6 \mathrm{~mm}$ column

408 containing $5 \mu \mathrm{m}$ particles and a $4.6 \mathrm{~mm} \times 20 \mathrm{~mm}$ guard column) using an Agilent 1200 HPLC

409 System. The sample loaded onto the C18 column was washed for 15 min with Solvent A (10

$410 \mathrm{mM}$ ammonium formate, adjusted to $\mathrm{pH} 10$ with ammonium hydroxide). The LC gradient started

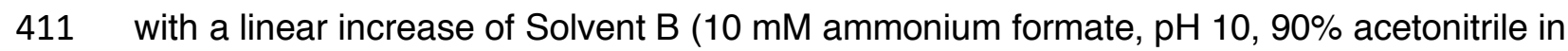

412 water) to: $5 \%$ over $10 \mathrm{~min}, 45 \%$ Solvent B over $65 \mathrm{~min}$, and then a linear increase to $100 \%$

413 Solvent B over 15 min. Solvent B was held at $100 \%$ for $10 \mathrm{~min}$, and then was changed to $100 \%$

414 Solvent $\mathrm{A}$, this being held for $20 \mathrm{~min}$ to recondition the column. The flow rate was $0.5 \mathrm{~mL} / \mathrm{min}$.

415 A total of 96 fractions were collected into a 96 well plate throughout the LC gradient. The high

$416 \mathrm{pH}$ RP fractions were then combined into 12 fractions using the concatenation strategy

417 previously reported ${ }^{37}$. Peptide fractions were dried down and re-suspended in nanopure water

418 at a concentration of $0.075 \mu \mathrm{g} / \mu \mathrm{L}$ for mass spectrometry analysis using a Q Exactive HF Hybrid

419 Quadrupole-Orbitrap MS (Thermo Scientific) system as described below.

\section{$421 \quad$ Mass-Spectrometry Based Analysis of Samples}

422 All peptide samples were analyzed using an automated home-built constant flow nano

423 LC system (Agilent) coupled to an Q Exactive HF Hybrid Quadrupole-Orbitrap MS (Thermo

424 Fisher Scientific). Electrospray emitters were custom made using $150 \mu \mathrm{m}$ o.d. x $20 \mu \mathrm{m}$ o.d. $\mathrm{x}$ 
$42520 \mu \mathrm{m}$ i.d. chemically etched fused silica. An on-line 4-cm x $360 \mu \mathrm{m}$ o.d. $x 150 \mu \mathrm{m}$ i.d. fused-

426 silica capillary analytical column (3 $\mu \mathrm{m}$ Jupiter $\mathrm{C} 18)$ was used. Mobile phases consisted of

$4270.1 \%$ formic acid in water $(\mathrm{A})$ and $0.1 \%$ formic acid acetonitrile $(\mathrm{B})$ operated at $300 \mathrm{~nL} / \mathrm{min}$ with

428 a gradient profile as follows (min:\%B); 0:5, 2:8, 20:12, 75:35, 97:60, 100:85.

430 Peptide Identification, Quantification and Analysis

431 For peptide identification, MS/MS spectra were searched against a decoy O. tauri

432 database using the algorithm SEQUEST. An approach to correlate tandem mass spectral data

433 of peptides with amino acid sequences in a protein database ${ }^{38}$. Search parameters included: no

434 enzyme specificity for proteome data and trypsin enzyme specificity with a maximum of two

435 missed cleaves, $\pm 50 \mathrm{ppm}$ precursor mass tolerance, $\pm 0.05 \mathrm{Da}$ product mass tolerance, and

436 carbamidomethylation of cysteines and iTRAQ labeling of lysines and peptide N-termini as fixed

437 modifications. Allowed variable modifications were oxidation of methionine. MSGF+ spectra

438 probability values were also calculated for peptides identified from SEQUEST searches ${ }^{39}$.

439 Measured mass accuracy and MSGF spectra probability were used to filter identified peptides to

$440<0.4 \%$ false discovery rate (FDR) at spectrum level and $<1 \%$ FDR at the peptide level using the

441 decoy approach. iTRAQ reporter ions were extracted using the MASIC software ${ }^{40}$ for fast

442 quantitation and flexible visualization of chromatographic profiles from detected LC-MS(/MS)

443 features with a 10-ppm mass tolerance for each expected iTRAQ reporter ion as determined

444 from each MS/MS spectrum.

445 Relative abundances of peptides were determined using iTRAQ reporter ion intensity

446 ratios from each MS/MS spectrum. Individual peptide intensity values were determined by

447 dividing the base peak intensity by the relative ratio associated with each reporter ion. All

448 peptide values were then transformed into log2 values for comparison between conditions. 


\section{Acknowledgements:}

This research was performed using the Environmental Molecular Sciences Laboratory (EMSL), a national scientific user facility sponsored by the Department of Energy's Office of Biological and Environmental Research and located at PNNL. This research also used resources of the Advanced Light Source, which is a DOE Office of Science User Facility under contract no. DEAC02-05CH11231.

\section{Funding}

This work was supported by DOE-BER Mesoscale to Molecules Bioimaging Project FWP\# 66382.

Competing Interests: We declare no competing interests.

\section{Contributions}

JEE devised and managed all experiments with input from CRS. CRS conducted confocal and Raman imaging experiments and coordinated integrated omics analysis. KKH and CDN performed lipid and proteomics sample prep. RM collected proteomics data that SP analyzed, and NK and WRC worked into the cell model. JEK performed lipidomic data collection and lipidomic analysis. Cryogenic soft X-ray sample preparation was conducted by JHC, RB and CRS with $\mathrm{JHC}$ and GM acquiring tilt series for subsequent reconstruction by AE. FACS analysis was conducted by WC. JEE and CRS wrote initial manuscript and all authors edited and approved final text.

\section{References}


1 Gimpel, J. A., Henriquez, V. \& Mayfield, S. P. In Metabolic Engineering of Eukaryotic Microalgae: Potential and Challenges Come with Great Diversity. Front Microbiol 6, 1376, doi:10.3389/fmicb.2015.01376 (2015).

2 Wase, N., Tu, B., Allen, J. W., Black, P. N. \& DiRusso, C. C. Identification and Metabolite Profiling of Chemical Activators of Lipid Accumulation in Green Algae. Plant Physiol 174, 2146-2165, doi:10.1104/pp.17.00433 (2017).

3 Longworth, J., Wu, D., Huete-Ortega, M., Wright, P. C. \& Vaidyanathan, S. Proteome response of Phaeodactylum tricornutum, during lipid accumulation induced by nitrogen depletion. Algal Res 18, 213-224, doi:10.1016/j.algal.2016.06.015 (2016).

4 Levering, J., Broddrick, J. \& Zengler, K. Engineering of oleaginous organisms for lipid production. Curr Opin Biotechnol 36, 32-39, doi:10.1016/j.copbio.2015.08.001 (2015).

5 Liao, J. C., Mi, L., Pontrelli, S. \& Luo, S. Fuelling the future: microbial engineering for the production of sustainable biofuels. Nat Rev Microbiol 14, 288-304, doi:10.1038/nrmicro.2016.32 (2016).

6 Goncalves, E. C., Wilkie, A. C., Kirst, M. \& Rathinasabapathi, B. Metabolic regulation of triacylglycerol accumulation in the green algae: identification of potential targets for engineering to improve oil yield. Plant Biotechnol J 14, 1649-1660, doi:10.1111/pbi.12523 (2016).

7 Klok, A. J., Martens, D. E., Wijffels, R. H. \& Lamers, P. P. Simultaneous growth and neutral lipid accumulation in microalgae. Bioresour Technol 134, 233-243, doi:10.1016/j.biortech.2013.02.006 (2013).

8 Griffiths, M. J., van Hille, R. P. \& Harrison, S. T. L. Lipid productivity, settling potential and fatty acid profile of 11 microalgal species grown under nitrogen replete and limited conditions. J Appl Phycol 24, 989-1001 (2012).

9 Guarnieri, M. T., Nag, A., Yang, S. \& Pienkos, P. T. Proteomic analysis of Chlorella vulgaris: potential targets for enhanced lipid accumulation. J Proteomics 93, 245-253, doi:10.1016/j.jprot.2013.05.025 (2013).

10 Minhas, A. K., Hodgson, P., Barrow, C. J. \& Adholeya, A. A Review on the Assessment of Stress Conditions for Simultaneous Production of Microalgal Lipids and Carotenoids. Front Microbiol 7, 546, doi:10.3389/fmicb.2016.00546 (2016).

11 Martin, S. F., Munagapati, V. S., Salvo-Chirnside, E., Kerr, L. E. \& Le Bihan, T. Proteome turnover in the green alga Ostreococcus tauri by time course $15 \mathrm{~N}$ metabolic labeling mass spectrometry. J Proteome Res 11, 476-486, doi:10.1021/pr2009302 (2012).

12 Lohman, E. J. et al. Optimized inorganic carbon regime for enhanced growth and lipid accumulation in Chlorella vulgaris. Biotechnol Biofuels 8, 82, doi:10.1186/s13068-0150265-4 (2015).

13 Levering, J., Dupont, C. L., Allen, A. E., Palsson, B. O. \& Zengler, K. Integrated Regulatory and Metabolic Networks of the Marine Diatom Phaeodactylum tricornutum Predict the Response to Rising CO2 Levels. mSystems 2, doi:10.1128/mSystems.00142-16 (2017).

14 Chen, Y., Xu, C. \& Vaidyanathan, S. Microalgae: a robust "green bio-bridge" between energy and environment. Crit Rev Biotechnol, 1-18, doi:10.1080/07388551.2017.1355774 (2017).

15 O'Neill, J. S. et al. Circadian rhythms persist without transcription in a eukaryote. Nature 469, 554-558, doi:10.1038/nature09654 (2011). 
16 Leliaert, F., Verbruggen, H. \& Zechman, F. W. Into the deep: new discoveries at the base of the green plant phylogeny. Bioessays 33, 683-692, doi:10.1002/bies.201100035 (2011).

17 Courties, C. et al. Phylogenetic analysis and genome size of Ostreococcus tauri (Chlorophyta, Prasinophyceae). J Phycol 34, 844-849, doi:DOI 10.1046/j.15298817.1998.340844.x (1998).

18 Guillou, L. et al. Diversity of picoplanktonic prasinophytes assessed by direct nuclear SSU rDNA sequencing of environmental samples and novel isolates retrieved from oceanic and coastal marine ecosystems. Protist 155, 193-214, doi:10.1078/143446104774199592 (2004).

19 Cardol, P. et al. An original adaptation of photosynthesis in the marine green alga Ostreococcus. Proc Natl Acad Sci U S A 105, 7881-7886, doi:10.1073/pnas.0802762105 (2008).

20 Derelle, E. et al. Genome analysis of the smallest free-living eukaryote Ostreococcus tauri unveils many unique features. Proc Natl Acad Sci U S A 103, 11647-11652, doi:10.1073/pnas.0604795103 (2006).

21 Blanc-Mathieu, R. et al. Population genomics of picophytoplankton unveils novel chromosome hypervariability. Sci Adv 3, e1700239, doi:10.1126/sciadv.1700239 (2017).

22 Smallwood, C. R. et al. <em>Ostreococcus tauri</em $>$ is a high-lipid content green algae that extrudes clustered lipid droplets. bioRxiv, doi:10.1101/249052 (2018).

23 Le Bihan, T. et al. Label-free quantitative analysis of the casein kinase 2-responsive phosphoproteome of the marine minimal model species Ostreococcus tauri. Proteomics 15, 4135-4144, doi:10.1002/pmic.201500086 (2015).

24 McCoy, J. G. et al. Discovery of sarcosine dimethylglycine methyltransferase from Galdieria sulphuraria. Proteins 74, 368-377, doi:10.1002/prot.22147 (2009).

25 Luo, G. Z., Blanco, M. A., Greer, E. L., He, C. \& Shi, Y. DNA N(6)-methyladenine: a new epigenetic mark in eukaryotes? Nat Rev Mol Cell Biol 16, 705-710, doi:10.1038/nrm4076 (2015).

26 Degraeve-Guilbault, C. et al. Glycerolipid Characterization and Nutrient DeprivationAssociated Changes in the Green Picoalga Ostreococcus tauri. Plant Physiol 173, 20602080, doi:10.1104/pp.16.01467 (2017).

27 Shimojima, M. \& Ohta, H. Critical regulation of galactolipid synthesis controls membrane differentiation and remodeling in distinct plant organs and following environmental changes. Prog Lipid Res 50, 258-266, doi:10.1016/j.plipres.2011.03.001 (2011).

28 Schaller-Laudel, S. et al. Influence of thylakoid membrane lipids on the structure of aggregated light-harvesting complexes of the diatom Thalassiosira pseudonana and the green alga Mantoniella squamata. Physiol Plant 160, 339-358, doi:10.1111/ppl.12565 (2017).

29 Losh, J. L., Young, J. N. \& Morel, F. M. Rubisco is a small fraction of total protein in marine phytoplankton. The New phytologist 198, 52-58, doi:10.1111/nph.12143 (2013).

30 Noordally, Z. B. et al. Circadian protein regulation in the green lineage I. A phosphodawn anticipates light onset before proteins peak in daytime. bioRxiv, doi:10.1101/287862 (2018). 
31 Keller, M. D., Selvin, R. C., Claus, W. \& Guillard, R. R. L. Media for the Culture of Oceanic Ultraphytoplankton. J Phycol 23, 633-638 (1987).

$32 \mathrm{Ji}, \mathrm{Y}$. et al. Raman spectroscopy provides a rapid, non-invasive method for quantitation of starch in live, unicellular microalgae. Biotechnol J 9, 1512-1518, doi:10.1002/biot.201400165 (2014).

33 Le Gros, M. A. et al. Biological soft X-ray tomography on beamline 2.1 at the Advanced Light Source. J Synchrotron Radiat 21, 1370-1377, doi:10.1107/S1600577514015033 (2014).

34 Parkinson, D. Y., Knoechel, C., Yang, C., Larabell, C. A. \& Le Gros, M. A. Automatic alignment and reconstruction of images for soft X-ray tomography. J Struct Biol 177, 259-266, doi:10.1016/j.jsb.2011.11.027 (2012).

35 Dautel, S. E. et al. Lipidomics reveals dramatic lipid compositional changes in the maturing postnatal lung. Sci Rep 7, 40555, doi:10.1038/srep40555 (2017).

36 Kyle, J. E. et al. LIQUID: an-open source software for identifying lipids in LC-MS/MSbased lipidomics data. Bioinformatics 33, 1744-1746, doi:10.1093/bioinformatics/btx046 (2017).

37 Wang, Y. et al. Reversed-phase chromatography with multiple fraction concatenation strategy for proteome profiling of human MCF10A cells. Proteomics 11, 2019-2026, doi:10.1002/pmic.201000722 (2011).

38 Eng, J. K., McCormack, A. L. \& Yates, J. R. An approach to correlate tandem mass spectral data of peptides with amino acid sequences in a protein database. J Am Soc Mass Spectrom 5, 976-989, doi:10.1016/1044-0305(94)80016-2 (1994).

39 Kim, S., Gupta, N. \& Pevzner, P. A. Spectral probabilities and generating functions of tandem mass spectra: a strike against decoy databases. J Proteome Res 7, 3354-3363, doi:10.1021/pr8001244 (2008).

40 Monroe, M. E., Shaw, J. L., Daly, D. S., Adkins, J. N. \& Smith, R. D. MASIC: a software program for fast quantitation and flexible visualization of chromatographic profiles from detected LC-MS(/MS) features. Comput Biol Chem 32, 215-217, doi:10.1016/j.compbiolchem.2008.02.006 (2008). 
bioRxiv preprint doi: https://doi.org/10.1101/293704; this version posted April 21, 2018. The copyright holder for this preprint (which was not certified by peer review) is the author/funder. All rights reserved. No reuse allowed without permission.

\section{Main Figures}

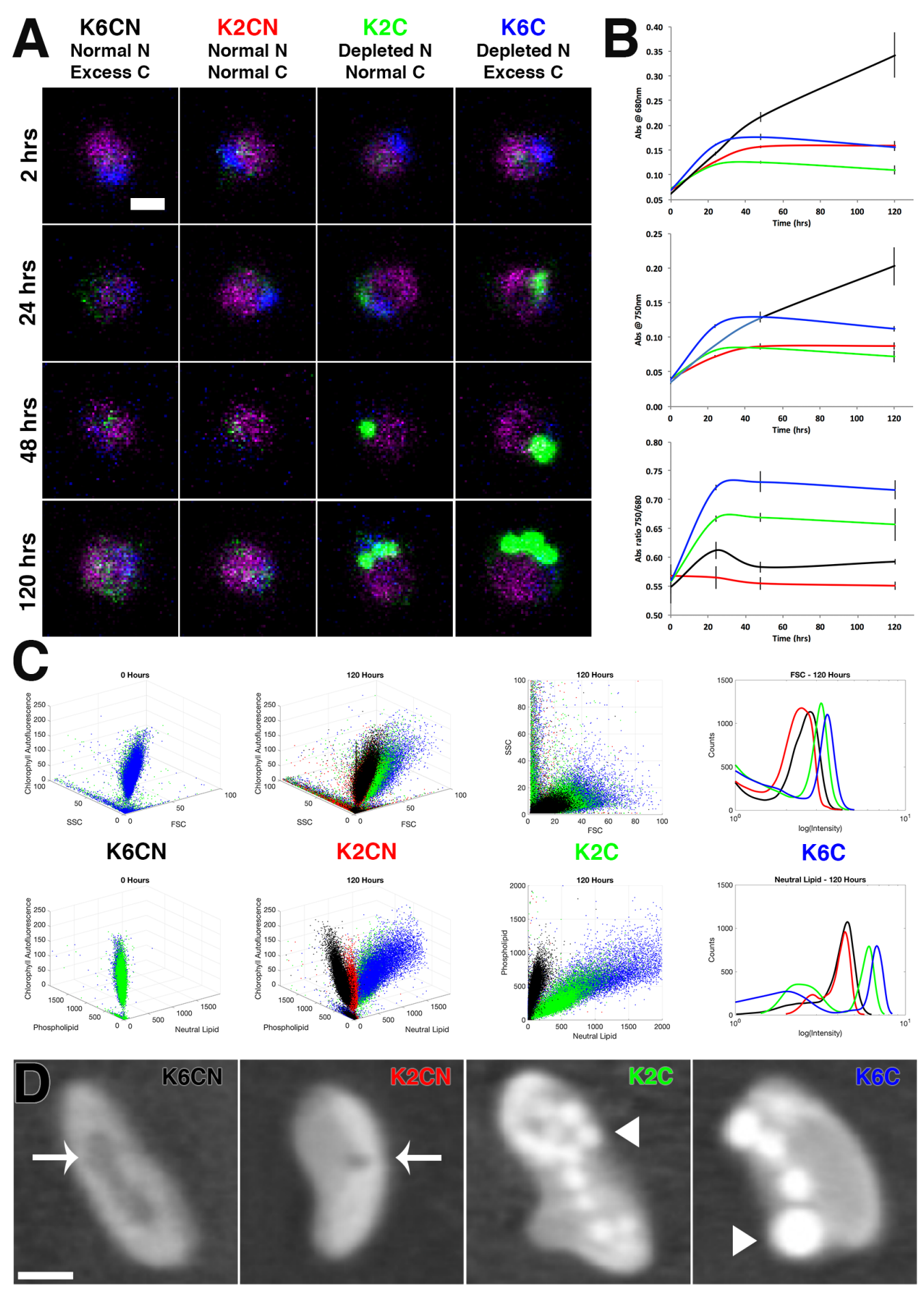

Figure 1 Single cell and population imaging and growth under varying $\mathrm{C}: \mathrm{N}$ ratios

(A) Confocal microscopy of $\mathrm{K} 6 \mathrm{CN}, \mathrm{K} 2 \mathrm{CN}, \mathrm{K} 2 \mathrm{C}$, and $\mathrm{K} 6 \mathrm{C}$ cultures to observe chlorophyll autofluorescence (magenta), nucleic acid fluorescent staining (blue), neutral lipid fluorescent staining (green) over time. Scale bar represents $1 \mu \mathrm{m}$ scale. (B) Corresponding growth plots for the same cultures monitored over time (error bars represent a replicate of 5) at 750nm and $680 \mathrm{~nm}$, and the ratio of the 750/680 as a measure of photosynthetic efficiency. (C) FACS time course study of same cultures comparing SSC (side-scattering) versus FSC (forward scattering) and chlorophyll autofluorescence in 3D plots at 0 hours and 120 hours, then 2D plot of SSC versus FSC at 120 hours, and histogram of FSC at 120 hours. (D) FACS time course study of same 
cultures comparing phospholipid versus neutral lipid and chlorophyll autofluorescence in 3D plots at 0 hours and 120 hours, then 2D plot of phospholipid versus neutral lipid at 120 hours, and histogram of neutral lipid at 120 hours. (E) Label-free cryogenic soft $x$-ray nanotomography images of cells cryogenically frozen in microcapillaries. Central slices ( $1 \mu \mathrm{m}$ scale bar) display intracellular structures common to each culture condition. Chloroplasts and cytoplasm seen in all images. Vacuoles in $\mathrm{K} 6 \mathrm{CN}$ and $\mathrm{K} 2 \mathrm{CN}$ appear as dark objects indicated with white arrow. Lipid droplets appear as bright white circular objects indicated by white arrowhead.

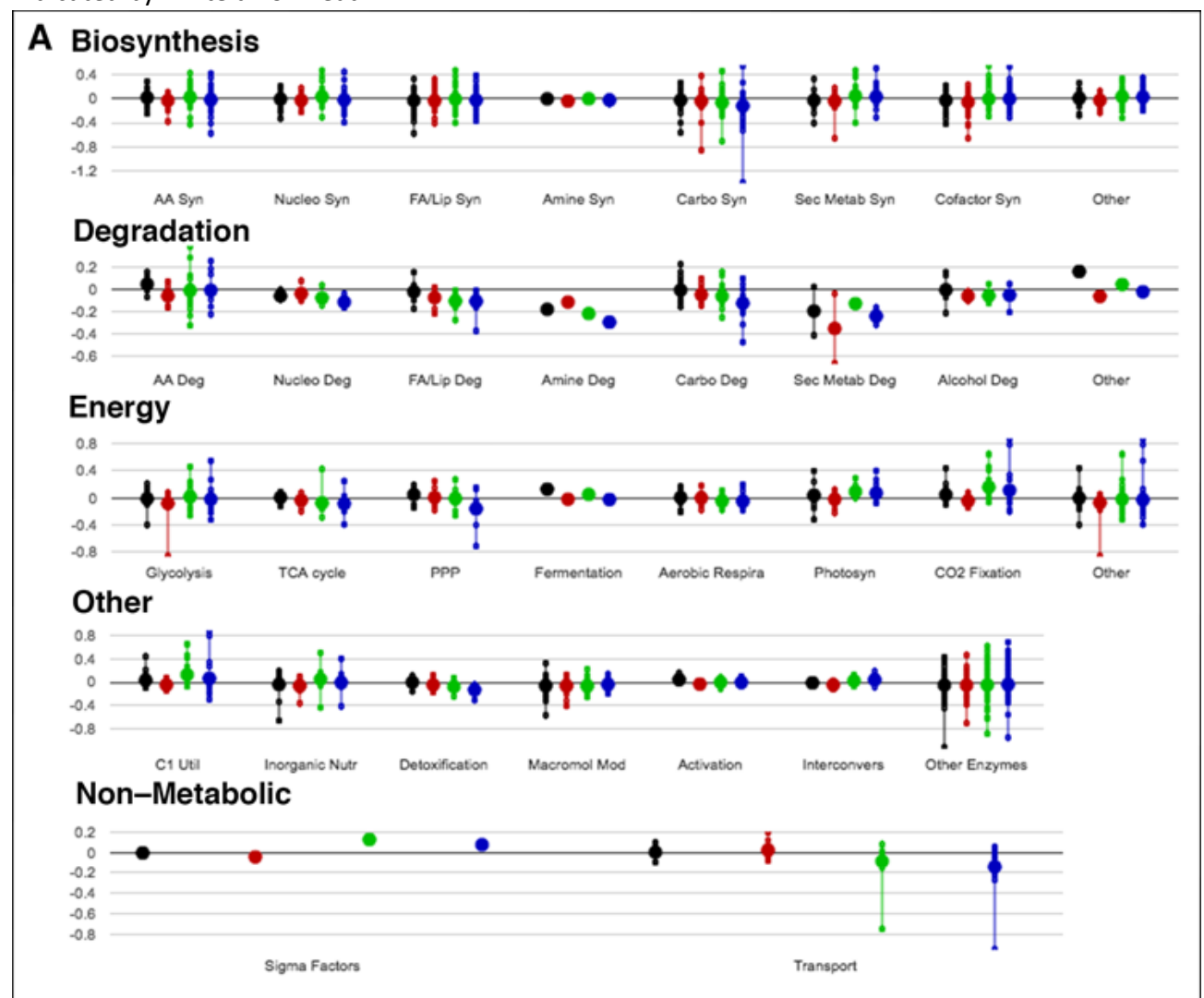

B Carbohydrate Biosynthesis

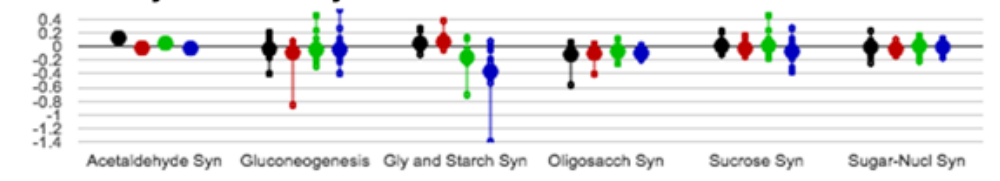

\section{Glycogen and Starch Synthesis}

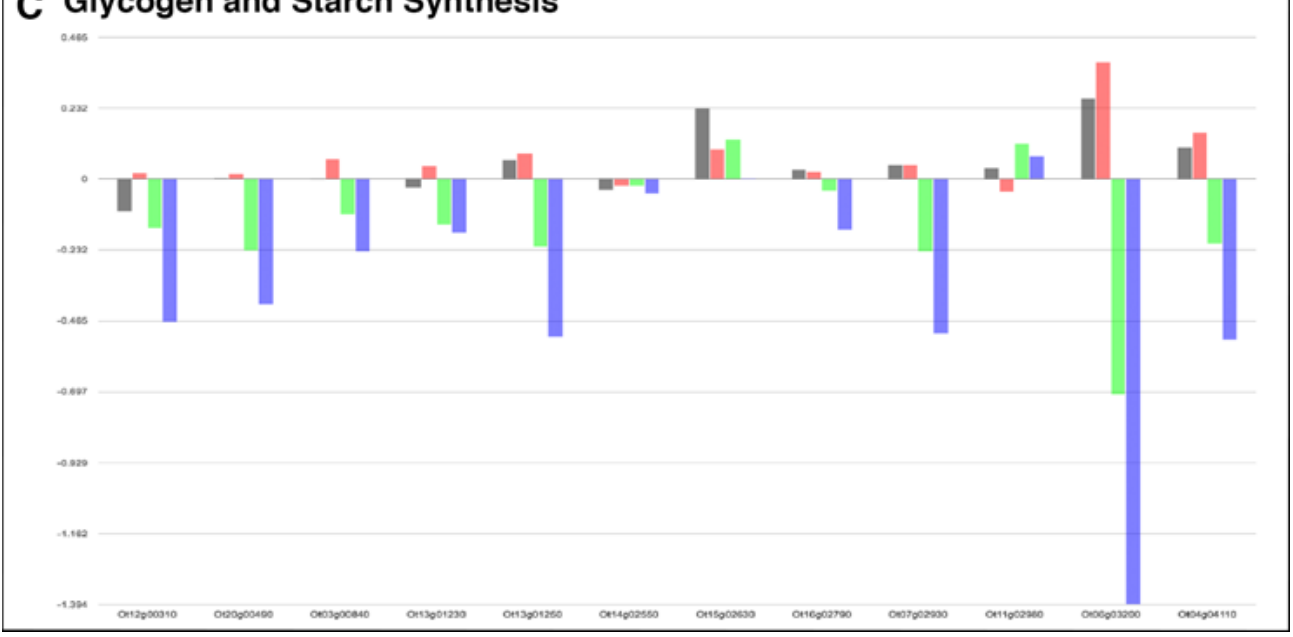


bioRxiv preprint doi: https://doi.org/10.1101/293704; this version posted April 21, 2018. The copyright holder for this preprint (which was not certified by peer review) is the author/funder. All rights reserved. No reuse allowed without permission.

Figure 2 Metabolic pathway mapping of global proteomics

O. tauri cells cultured in $\mathrm{K} 6 \mathrm{CN}$ (black), $\mathrm{K} 2 \mathrm{CN}$ (red), $\mathrm{K} 2 \mathrm{C}$ (green), $\mathrm{K} 6 \mathrm{C}$ (blue) at 48 hours relative to cultures from $\mathrm{K} 2 \mathrm{CN}$ at 24 hours were grouped and mapped by metabolic pathway(A), subpathway (B), and individual proteins (C). Each large circle represents an average level of abundance on a log2 scale where negative values are increases in abundance relative to cell conditions $\mathrm{K} 2 \mathrm{CN}$ at 24 hours. Smaller circles represent individual proteins in the respective metabolic pathway.

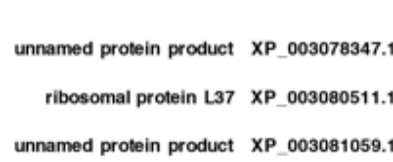

Ribulose-1,5-bisphosphate carboxyase/oxygenase small subunit XP_003084234.1

unnamed protein product XP_003075209.1

ribulose-1,5-bisphosphate carboxylase/oxygenase large subunit (chloroplast) YP_717262.1 40 S ribosomal protein S16 XP_003079490.1

ribosomal protein L18 XP_003081305.

60S ribosomal protein L3.e XP_003074108.1

RL23A FRIAG 60 S ribosomal protein L23A XP 003080973.1

Predicted membrane protein XP_003080099.1

unnamed protein product XP_003082699.1

unnamed protein product XP_003082140.1

putative deaminase XP 003078644.1

ammonium transporter XP_003084401.1

Dur3, urea high-affinity symporter XP_003083319.1

unnamed protein product XP_003084028.1

GBSSI, Granule-bound starch synthase I XP_003079933.1

unnamed protein product XP_003084215.1

STK, Serine/threonine protein kinase, putative XP_003083842.1

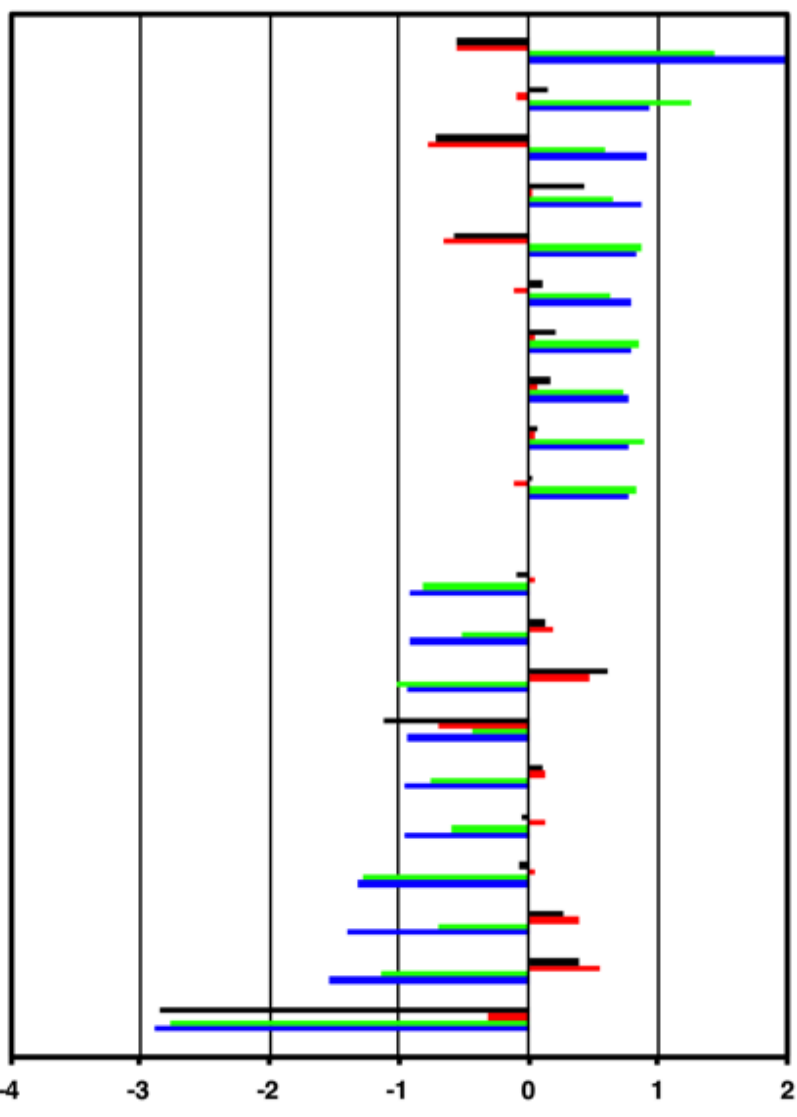

Relative Abundance to $\mathrm{K} 2 \mathrm{CN}$ at 24 hours

Figure 3 Selection differentially expressed proteins from global proteomics of varying $\mathbf{N}$ and $\mathbf{C}$ conditions

Abundance profiles for 10 most downregulated (positive values) and upregulated (negative values) proteins comparing K2CN at 24 hours versus $\mathrm{K} 6 \mathrm{CN}$ at 48 hours (black), $\mathrm{K} 2 \mathrm{CN}$ at 48 hours (red), $\mathrm{K} 2 \mathrm{C}$ at 48 hours (green), and $\mathrm{K} 6 \mathrm{C}$ at 48 hours (blue) cell cultures. 
bioRxiv preprint doi: https://doi.org/10.1101/293704; this version posted April 21, 2018. The copyright holder for this preprint (which was not certified by peer review) is the author/funder. All rights reserved. No reuse allowed without permission.

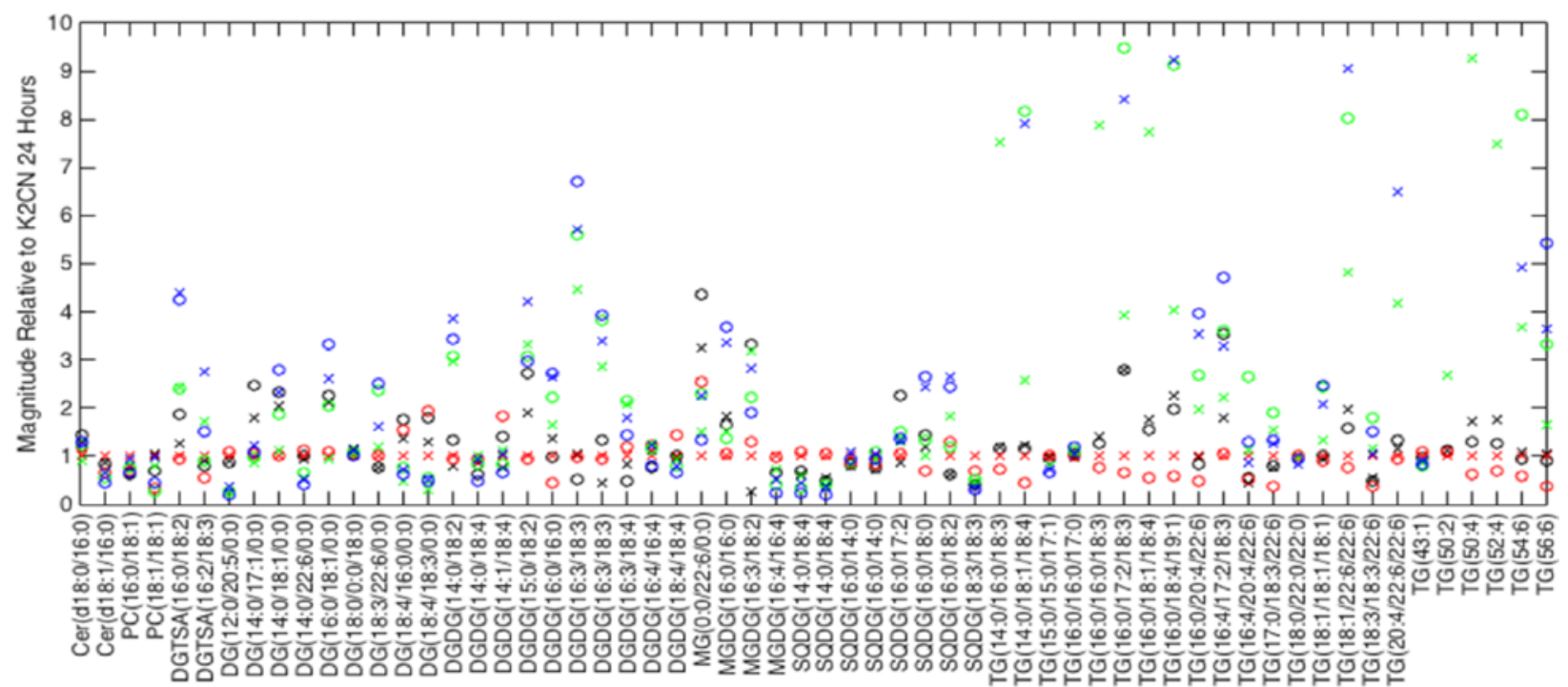

Figure 4 Time resolved differential expression of global lipids

Selection of lipids (out of 287) detected via LC-MS/MS for cell cultures at 24 (X symbols) and 48 hours (O symbols) for varying C:N ratio conditions K6CN (black), K2CN (red ), K2C (green) and K6C (blue). Cer: Ceramide; PC: phosphatidylcholine; MGDG: monogalactosyldiacylglycerol; DG: diacylglycerol; DGDG: digalactosyldiacylglycerol; DGTSA: diacylglyceryl trimethylhomoserine or diacylglyceryl trimethyl-beta-alanine; SQDG: sulfoquinovosyldiacylglycerol; and TG: triacylglycerols 


\section{Supplemental Figures}

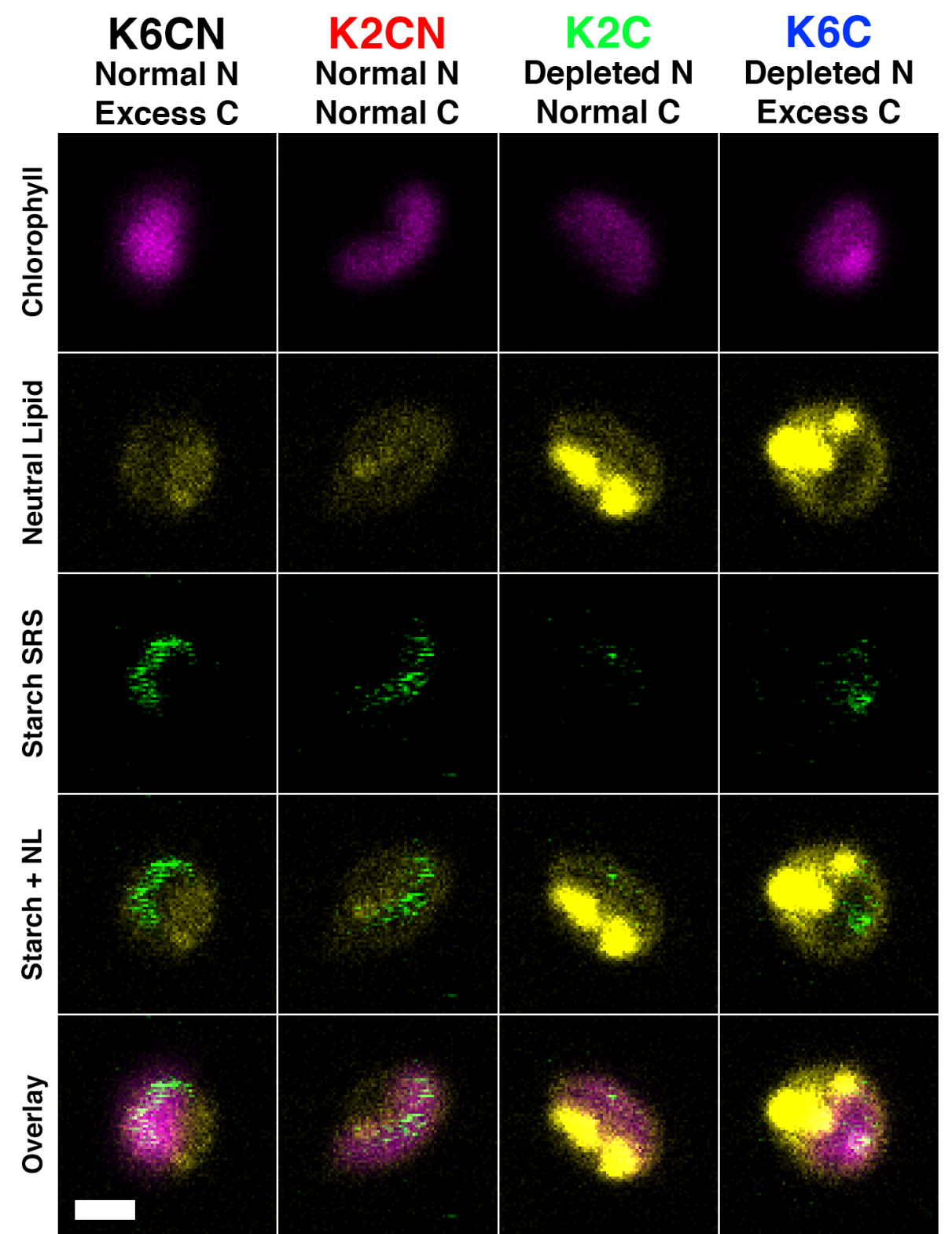

Supplemental Figure 1 Fluorescence and SRS verification of neutral lipid and starch accumulation

Fluorescence and SRS microscopy were conducted on $O$. tauri cells stained with Nile Red from various C:N conditions after 96 hours of starvation. Chlorophyll autofluorescence (pink) was observed in all cells with neutral lipid (yellow) and SRS starch signal (green). Elevated neutral lipid was observed in $\mathrm{K} 2 \mathrm{C}$ and $\mathrm{K} 6 \mathrm{C}$ cells localized outside the chloroplast. Starch was detected and localized to the chloroplast for $\mathrm{K} 6 \mathrm{CN}, \mathrm{K} 2 \mathrm{CN}$, and to a lesser extent $\mathrm{K} 6 \mathrm{C}$, with little to no starch signal found in $\mathrm{K} 2 \mathrm{C}$ cells. Scale bar represents $1 \mu \mathrm{m}$. 
t1

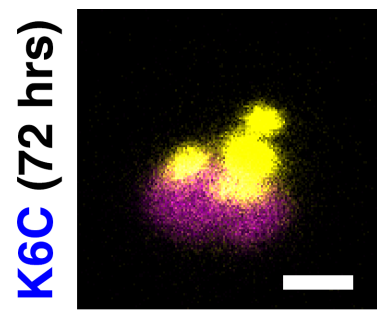

t2

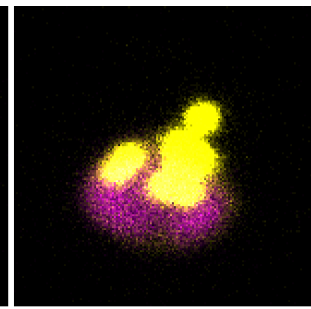

t3

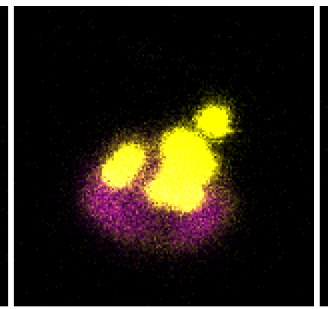

t4

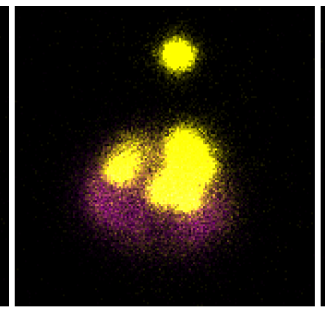

t5

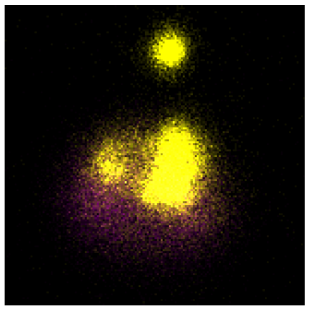

\section{Supplemental Figure 2 Time course of lipid release from cells into intercellular space}

O. tauri cells cultured in $\mathrm{K} 6 \mathrm{C}$ media for 72 hours were harvested and stained with Nile Red and then imaged by confocal fluorescence microscopy. Chlorophyll autofluorescence (pink) and neutral lipid (yellow) revealed many large lipid bodies during $z$-slice imaging and a single lipid body release was tracked over time $(\mathrm{t})$ in intercellular milieu while other lipids remained inside the intracellular space.

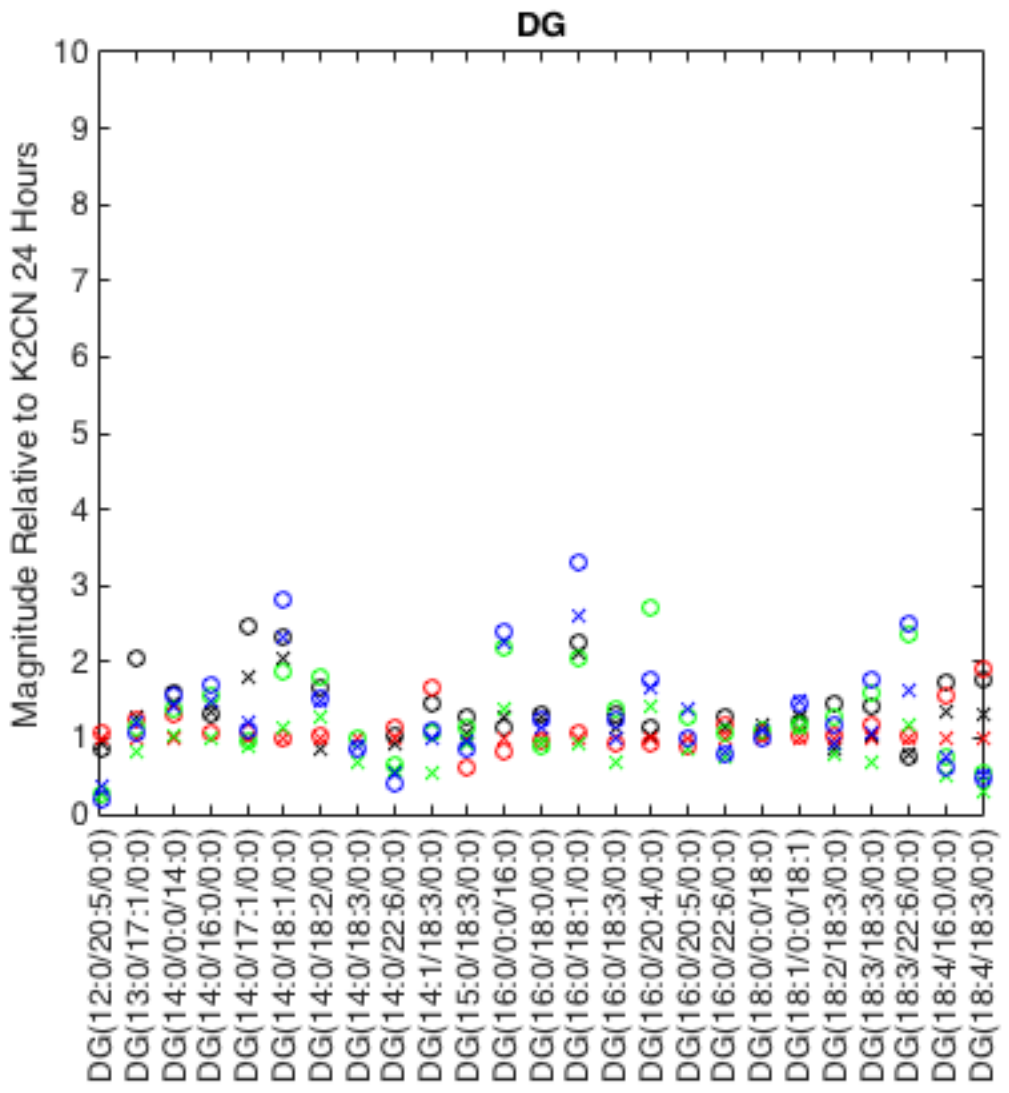

Supplemental Figure 3 Time-resolved lipidomics of diacylglycerol lipids

Diacylglycerol (DG) lipids detected via LC-MS/MS for cell cultures at 24 (X symbols) and 48 hours (O symbols) for varying C:N ratio conditions $\mathrm{K} 6 \mathrm{CN}$ (black), $\mathrm{K} 2 \mathrm{CN}$ (red ), $\mathrm{K} 2 \mathrm{C}$ (green) and $\mathrm{K} 6 \mathrm{C}$ (blue) relative to $\mathrm{K} 2 \mathrm{CN}$ at 24 hours (y-axis). 
bioRxiv preprint doi: https://doi.org/10.1101/293704; this version posted April 21, 2018. The copyright holder for this preprint (which was not certified by peer review) is the author/funder. All rights reserved. No reuse allowed without permission.

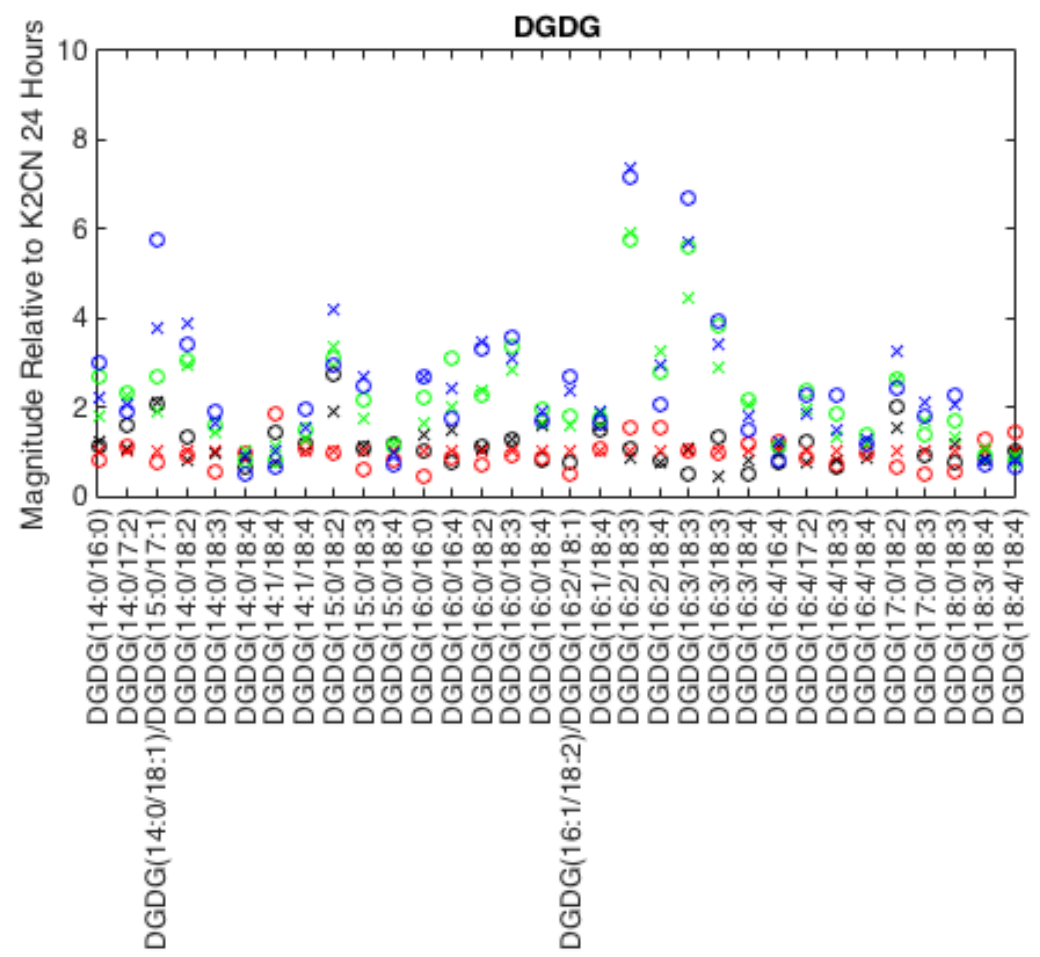

Supplemental Figure 4 Time resolved differential expression of digalactosyldiacylglycerol lipids Digalactosyldiacylglycerol (DGDG) lipids detected for cell cultures at 24 (X symbols) and 48 hours (O symbols) for varying C:N ratio conditions $\mathrm{K} 6 \mathrm{CN}$ (black), $\mathrm{K} 2 \mathrm{CN}$ (red), $\mathrm{K} 2 \mathrm{C}$ (green) and $\mathrm{K} 6 \mathrm{C}$ (blue) relative to $\mathrm{K} 2 \mathrm{CN}$ at 24 hours (y-axis). 


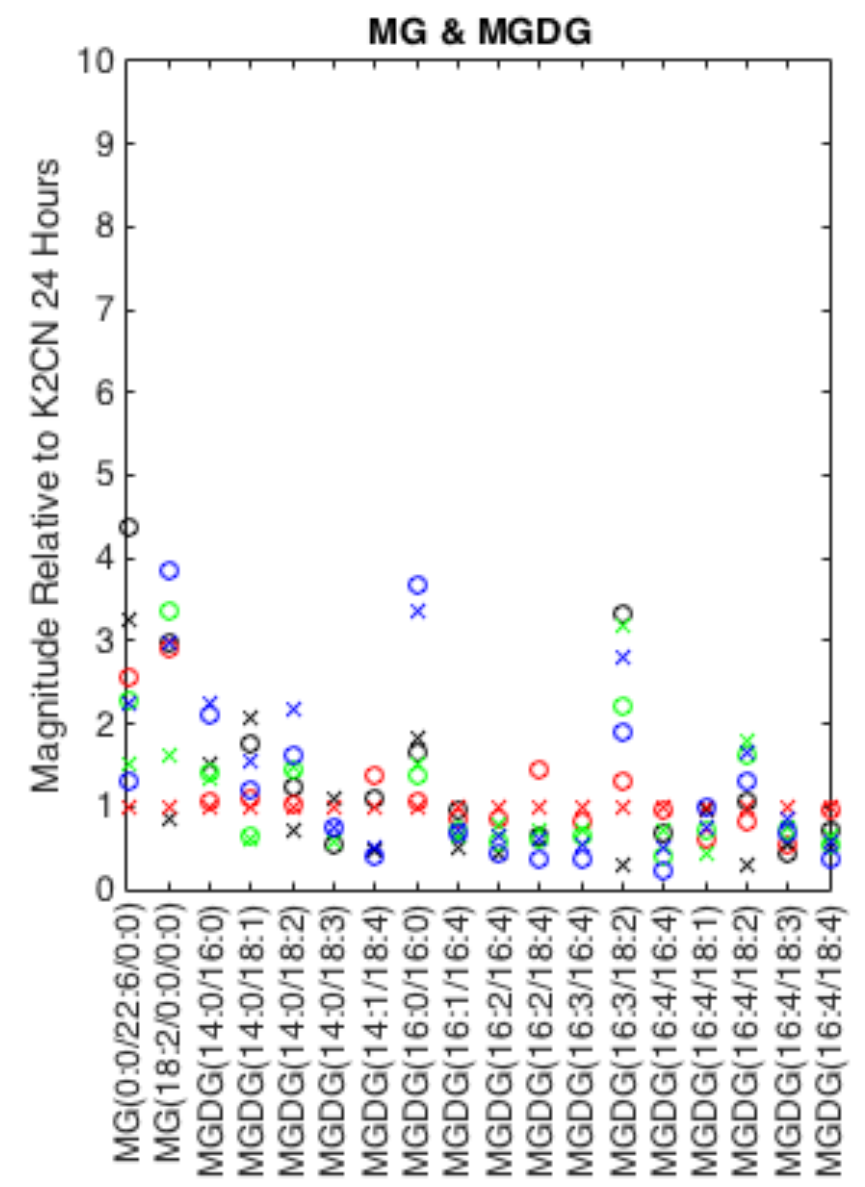

Supplemental Figure 5 Time resolved differential expression of monoacylglycerol and monogalactosyldiacylglycerol lipids Monoacylglycerol (MG) and monogalactosyldiacylglycerol (MGDG) lipids detected via LC-MS/MS for cell cultures at 24 (X symbols) and 48 hours (O symbols) for varying C:N ratio conditions $\mathrm{K} 6 \mathrm{CN}$ (black), $\mathrm{K} 2 \mathrm{CN}$ (red ), K2C (green) and K6C (blue) relative to $\mathrm{K} 2 \mathrm{CN}$ at 24 hours ( $\mathrm{y}$-axis). 


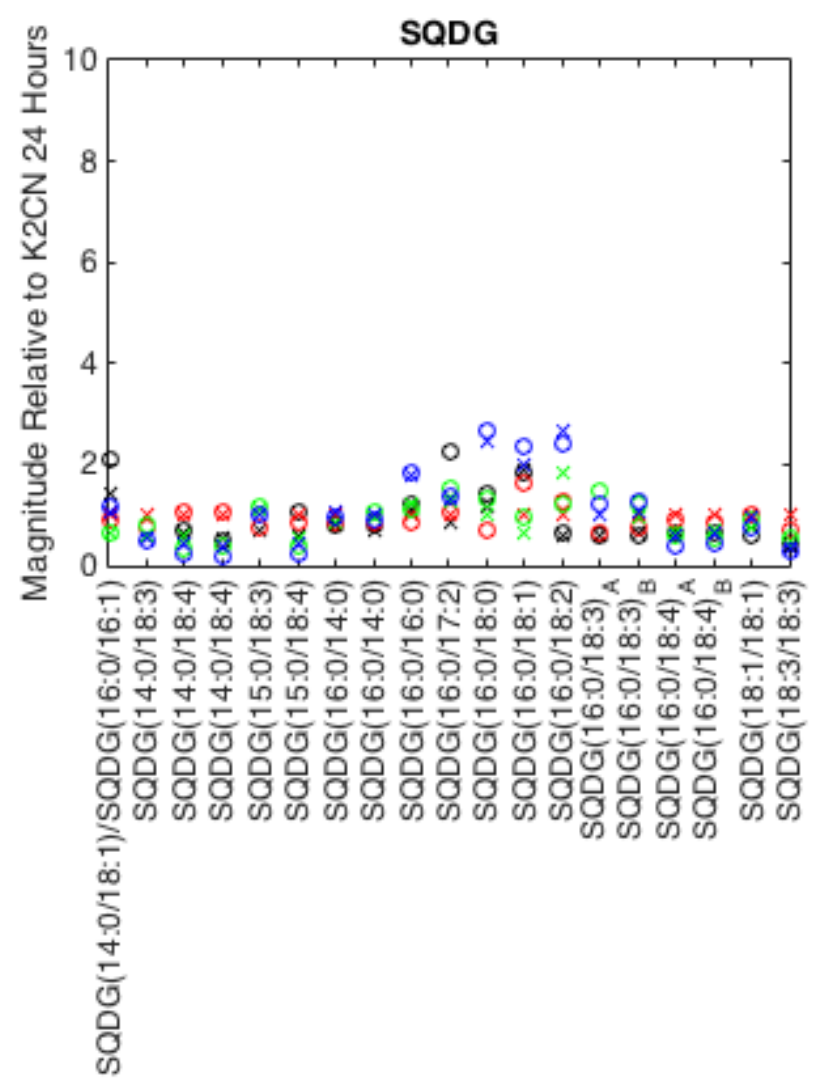

Supplemental Figure 6 Time resolved differential expression of lipids

Sulfoquinovosyldiacylglycerol (SQDG) lipids detected via LC-MS/MS for cell cultures at 24 (X symbols) and 48 hours (O symbols) for varying C:N ratio conditions K6CN (black), K2CN (red), K2C (green) and K6C (blue) relative to K2CN at 24 hours (y-axis). 

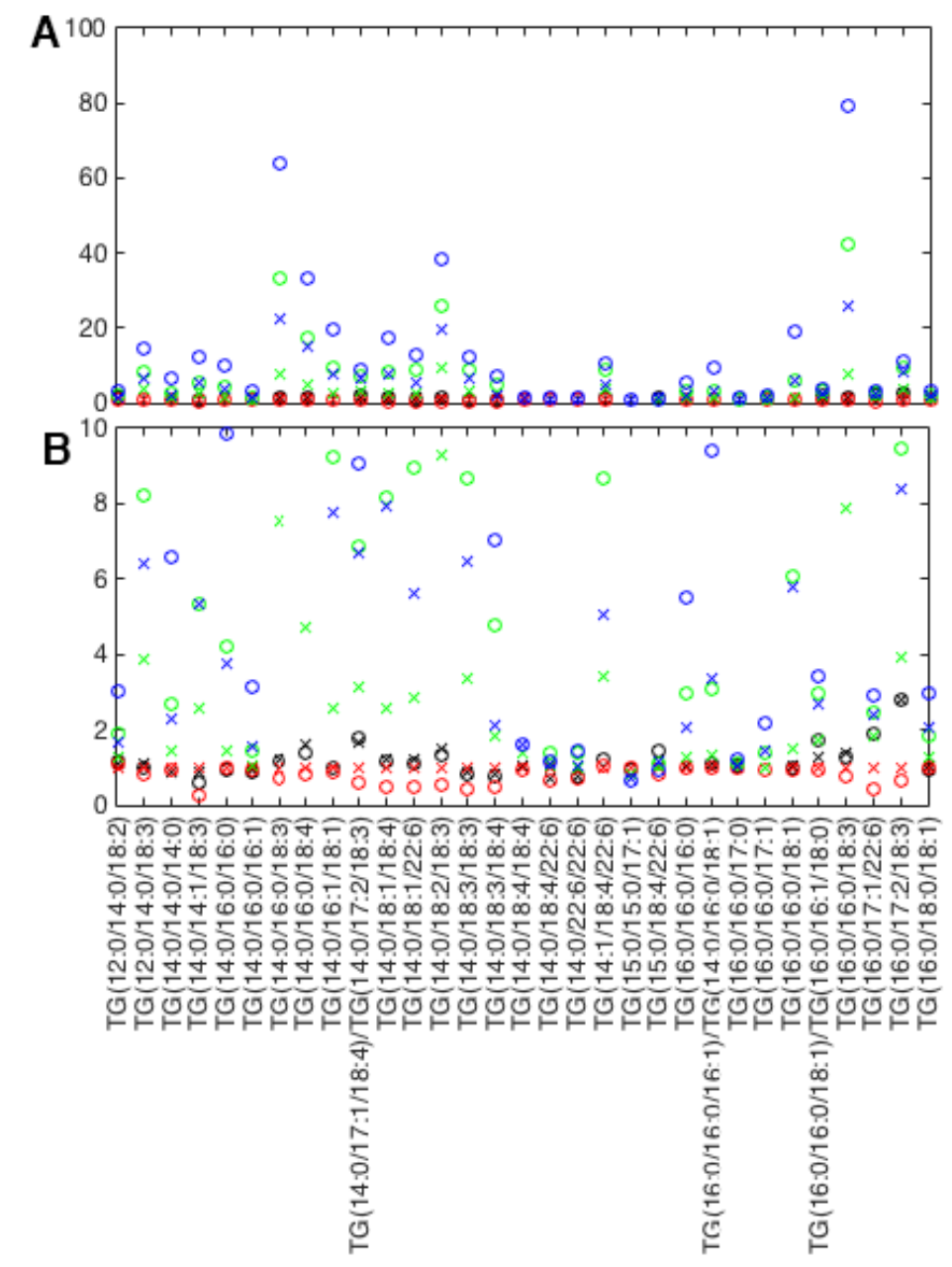

Supplemental Figure 7 Time resolved differential abundance of triacylglycerol lipids set 1 Triacylglycerol (TG) lipidomics for cell cultures at 24 (X symbols) and 48 hours (O symbols) for varying C:N ratio conditions K6CN (black), $\mathrm{K} 2 \mathrm{CN}$ (red), $\mathrm{K} 2 \mathrm{C}$ (green) and $\mathrm{K} 6 \mathrm{C}$ (blue) relative to $\mathrm{K} 2 \mathrm{CN}$ at 24 hours (y-axis). 
bioRxiv preprint doi: https://doi.org/10.1101/293704; this version posted April 21,2018 . The copyright holder for this preprint (which was not certified by peer review) is the author/funder. All rights reserved. No reuse allowed without permission.
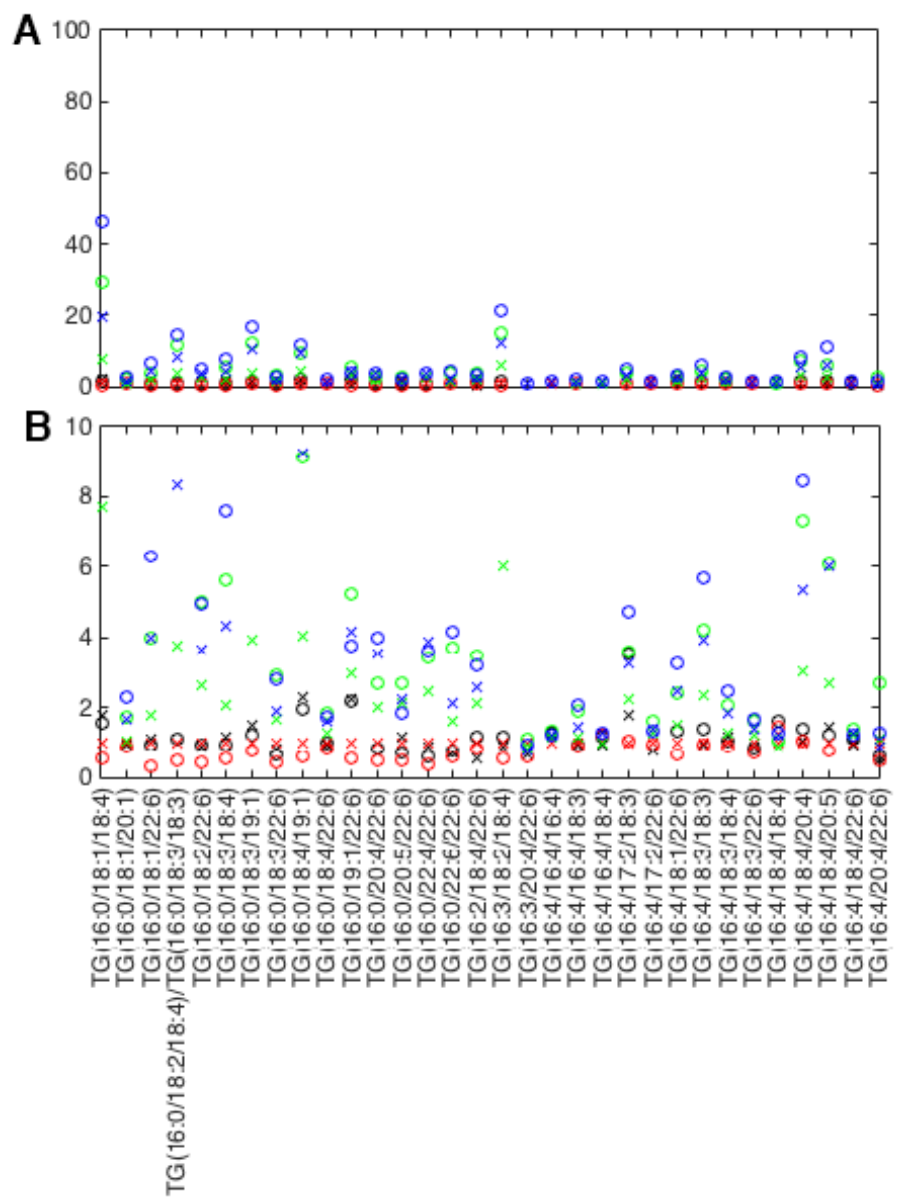

Supplemental Figure 8 Time resolved differential abundance of triacylglycerol lipids, set 2

Triacylglycerol (TG) lipidomics detected via LC-MS/MS for cell cultures at 24 (X symbols) and 48 hours (O symbols) for varying $\mathrm{C}: \mathrm{N}$ ratio conditions $\mathrm{K} 6 \mathrm{CN}$ (black), $\mathrm{K} 2 \mathrm{CN}$ (red ), $\mathrm{K} 2 \mathrm{C}$ (green) and $\mathrm{K} 6 \mathrm{C}$ (blue) relative to $\mathrm{K} 2 \mathrm{CN}$ at 24 hours (y-axis). 

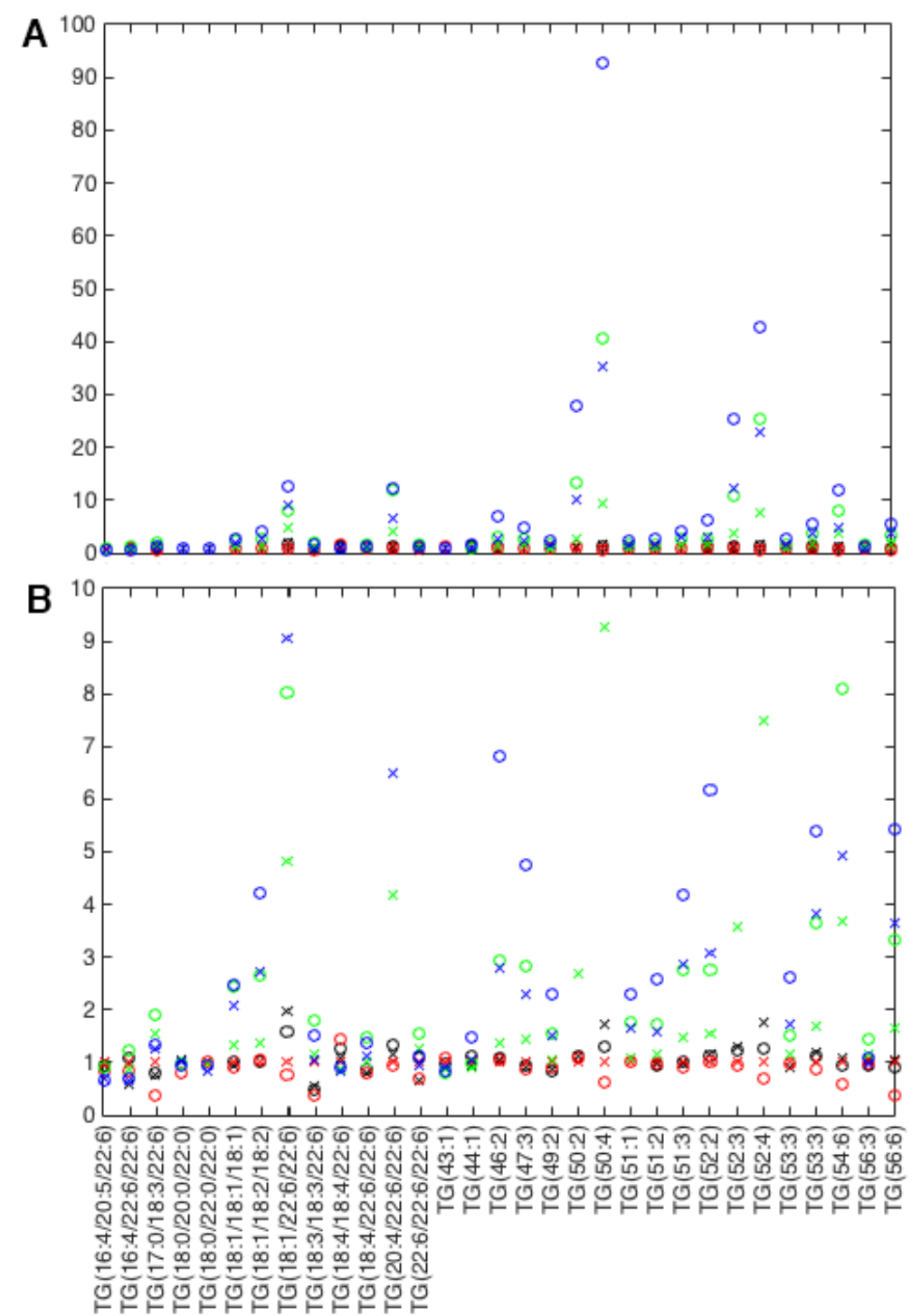

Supplemental Figure 9 Time resolved differential abundance of long chain triacylglycerol lipids, scale 10 Long chain triacylglycerol (TG) lipidomics for cell cultures at 24 (X symbols) and 48 hours (O symbols) for varying C:N ratio conditions $\mathrm{K} 6 \mathrm{CN}$ (black), $\mathrm{K} 2 \mathrm{CN}$ (red ), $\mathrm{K} 2 \mathrm{C}$ (green) and $\mathrm{K} 6 \mathrm{C}$ (blue) relative to $\mathrm{K} 2 \mathrm{CN}$ at 24 hours (y-axis). 